\title{
Evaluating the Impact of Government Policies and Regulations on M-Commerce in India: A System Dynamics Modelling Approach
}

\author{
Deepali Sharma $^{1}$, Diatha Krishna Sundar ${ }^{2} \&$ Rajluxmi V. Murthy ${ }^{3}$ \\ ${ }^{1}$ Deepali Sharma, Broadcasting Corporation of India, India \\ ${ }^{2}$ Chairperson-POMA \& Chairperson-ERP Center, Indian Institute of Management Bangalore, India \\ ${ }^{3}$ Indian Institute of Management Bangalore, India \\ Correspondence: Diatha Krishna Sundar, Chairperson-POMA \& Chairperson-ERP Center, Indian Institute of \\ Management Bangalore, Bannerghatta Road, Bangalore 560076, India. Tel: 91-802-699-3276. E-mail: \\ diatha@iimb.ernet.in
}

Received: July 31, 2012

doi:10.5539/ijbm.v7n23p54

Accepted: September 20, 2012

Online Published: November 8, 2012

URL: http://dx.doi.org/10.5539/ijbm.v7n23p54

\begin{abstract}
Mobile Commerce (M-Commerce) is a subset of E-Commerce, which includes all E-Commerce transactions, carried out using mobile (handheld) device(s). With significant uncertainties and complexities due to evolving business and regulatory models, growth of M-Commerce is a function of appropriate and timely policy interventions from the government(s). M-Commerce business growth is further complicated by the involvement of several interrelated stake-holders and various regulatory agencies that are part of the M-Commerce eco-system, which comprises of mobile telecom service providers, banking/financial institutions, content facilitators, retailers, mobile terminal industry, and end users as the major stake-holders. To understand the M-Commerce growth facilitators in India, where M-Commerce is at its infancy, system dynamics simulation models are developed. The simulation models are used to analyze the impact of policy and regulatory interventions on the growth of M-Commerce in India. These models can help policy makers in understanding the inter-play between various independent regulatory/policy approaches and assessing their impact in a holistic manner on the business eco-system.
\end{abstract}

Keywords: M-Commerce, policy interventions, regulation, system dynamics, simulation

\section{Introduction}

The merger of telecom, broadcasting and IT Services has resulted in formation of Global Information Infrastructure (GII) which is capable of carrying any type of information. Wireless technologies and devices have further enhanced the capabilities of GII by facilitating wireless information carriage advancing the concept of e-economy to mobile domain. The counterparts of E-Commerce in the mobile domain are termed as M-Commerce (Sundar et al., 2002; Sundar \& Garg 2005a; Sundar et al., 2005b). M-Commerce is convergence of mobile telecom (including network and receiving devices), computing power, internet technologies \& applications and content provision (Lehner \& Watson, 2001; Mylonopoulos \& Doukidis, 2003) and refers to, "any transaction with monetary value that is conducted via a mobile network" (Clarke, 2001). M-Commerce has many advantages associated with it such as reduced transaction costs, wider access on both supply and demand side, improved quality of life through increased security and autonomy, wider choices of entertainment, communication, shopping while on move, location based services, ease and convenience of use and so on. M-Commerce is expected to play an important role in economic and social development of a country (Krishnamurthy, 2001). Growth in M-Commerce brings down transaction costs besides increasing the reach and scope of business. This leads to enhanced productivity of related industry verticals and in turn Gross Domestic Product (GDP) of a nation. Using global telecommunications panel data from 56 countries, a dynamic demand model was estimated for mobile telephony (Madden et al.2004). A direct relationship between average GDP growth and mobile penetration was established based on the data collected from 57 developing countries from Sub-Saharan countries, Latin America, Middle East and Asia Pacific along with 15 European Union countries (GSM Association Report, 2006). With respect to India, it is estimated that $10 \%$ increase in mobile penetration can translate to a $0.61 \%$ increase in GDP (McKinsey, 2006). Increase in mobile penetration will increase M-Commerce uptake and is expected to influence GDP.

The growth of the M-Commerce industry is powered by synergies between various stakeholders/players such as 
media, mobile, content and service providers and aggregators of these along with appropriate payment mechanisms. In the M-Commerce domain, many applications and services are possible and the success of technology depends on the innovative services and content push. But as value enhanced services increase such as retail and content delivery on the communication value chain, the associated complexities and risks also increase (Henten et al., 2003; Samarajiva et al. 2002; Sundar et al., 2006). One of the thrust areas for M-Commerce growth is educating subscribers on the added value in consuming M-Commerce services which in turn will lead to mass mobile adoptions (Wong \& Hiew, 2005). Another important facilitator for mobile commerce is the presence of properly functioning payment systems that reduce transaction costs in the economy and promote the efficient use of financial resources (Bank for International Settlement, 2003).Various models for payments in M-domain are available (Salvi \& Sahai, 2002; Krueger, 2001) but the appropriate payment mechanisms would be influenced by customer and merchant acceptance (Heijden, 2002).

Appropriate policy frameworks and regulatory mechanisms/agencies are necessary for dealing with the complexities of enhanced services and stakeholder interrelatedness; and enabling payment mechanisms. Absence of appropriate policies would hamper the growth of the industry while a poorly regulated industry may result in high prices, inferior quality services to the consumers and prevalence of grey markets for handsets resulting in revenue losses for the government. Policies related to an industry are framed by the government to steer the industry growth in desired direction with an aim to benefit the state and its citizens. Regulation is a way to modify behaviour of individuals, organizations and businesses to work in a desired way, which is in the interest of society. Regulation is a "sustained and focused control exercised by a public agency over activities which are valued by a community" through specific set of commands, deliberate state influence and social control or influence (Baldwin and Martin, 1999). Regulation is thus used to achieve wider social goals such as equity, diversity or social solidarity and to hold powerful corporate, professional, or social interests to account (Walshe, 2002). Government tries to achieve its policy objectives through regulations by defining the codes of conduct, setting standards, monitoring and enforcing them. Hence it becomes obligatory on the part of the government to regulate these concerns with a multidisciplinary approach. To design a good regulatory framework and ensure reasonable level of compliance it is important to understand the characteristics of market, structuring of individual organizations and their interrelations in the setup and obstacles in their compliance (OECD, 2000).

Many technologies have been developed and marketed in last few years but only few have witnessed commercial success, irrespective of their potential and capacities. In a dynamic environment development of technology is followed by business applications further followed by regulations. Policies and regulations in advance are often not recommended fearing that excess control over a technology business in initial stages may reduce the number of economic experiments hampering its overall development. However, there is a need for policies and regulations to co-evolve with the technology and markets. India is an example of timely regulatory reforms inmobile telephone industry where the regulatory system co-evolved with technology and industry developments. The number of mobile subscribers stands at 893million in December 2011 (TRAI). The Mobile Value Added services (MVAS) besides plain voice services are increasingly gaining acceptance among users. MVAS revenues were estimated to contribute INR 51.3 billion in 2009-10and areexpected to grow at a CAGR of 21 percent in next five years(CRISINFAC 2010b). With these high growth rates and a multitude of stakeholders, M-Commerce in India requires advance regulatory framework to be designed that would synergize various stakeholders and act as a catalyst for further growth. This paper addresses the impact of policies and regulation on the growth of M-Commerce, with specific reference to India.

The Indian context in E-Commerce and M-Commerce is not very different from that of other developing countries. More than $65 \%$ of the Indian population resides in rural India with poor connectivity. Rural telecommunications system has to keep variety of concerns other than technological issues (Andrew, 2003) and also cellular network penetration on fixed line diffusion (Biancini, 2011). Extending last mile connectivity to these areas, which is required for e-governance, was a major bottleneck. This has been overcome to a great extent by wireless technologies as rural tele-density is nearly $36.5 \%$ (TRAI 2011) and an increased percentage (as high as $40 \%$ ) of new additions come from rural subscribers(CRISINFAC 2010a). It is further needed to facilitate convergence of media and technologies through proper regulatory and policy support. With the commercial introduction of digital mobile telephony in India in 1995, the diffusion of mobile telephony is different from the developed nations as it is a beneficiary of the size of customer base and also that of established standards (Rouvinen, 2006). Connectivity issues being resolved, policy and facilitation have become critical to bring in efficient and economic services in the M-domain.

Empirical research in many areas of M-Commerce is lacking because of considerable uncertainties (Okazaki, 
2005). Recent review on M-commerce research has identified the progress made so far and gaps for future research (Ngai, 2007). Lehner and Watson (2001) have prescribed various perspectives to conduct research on mobile commerce such as the stakeholder perspective, mobile commerce services perspective, applications perspective and the mobile commerce market players (Institutional) perspective. The stakeholder perspective was further extended to identify stakeholders and develop an M-Commerce business model (Sundar et al., 2006)

There is ample literature available on mobile commerce applications, services, statistics, business adoption and user acceptance related issues (Chu \& Lihua, 2005; Karjaluoto, 2006; Lin \& Wang, 2005; Udo, 2001; Varshney et al., 2000; Varshney \& Vetter, 2002; Wang et al., 2005). Out of 149 identified M-Commerce research and application papers, only seven dealt with legal and ethical issues in M-Commerce (Ngai \& Gunasekaran, 2007). However, literature on M-Commerce related policy aspects in the Indian context is not available as M-Commerce is still at a very nascent stage in India (Sharma, 2007). The M-Commerce eco-system is complex (Lee et al., 2003; Sundar et al., 2006) and it is difficult to analyze the socio-economic and political inter-relatedness of M-Commerce subsystems using qualitative and intuitive judgments. Econometric analysis and regression analysis, though can provide explanation for past behaviour, are inappropriate for analyzing socio-economic changes, nonlinear relationships and various interrelated factors (Wang \& Cheong, 2005a, 2005b).

Given the complexities involved in designing policies \& regulatory frameworks, taking stakeholders' interrelationships into account and understanding their impact on the stakeholders - Systems thinking is the most appropriate approach for analysing policies and their impact. Particularly, in the case of analysing policies for M-Commerce, it is all the more difficult as there are no historical precedence available. Systems thinking and SD modelling are best suited to address such situations.

"System dynamics model are noteworthy in the insistence on a high degree of structural realism and a high level of explanatory content relating system structure to observed behaviour patterns. Beyond objectives of forecasting or prediction, a system dynamics model is intended to yield operational insights about the feedback relations that can produce or contribute to problems, can counteract policy interventions, or can reinforce benefits of policy actions aimed at high leverage points. System dynamics modelling is the best forum for organizing complexity in public systems. Interactions can be identified, albeit somewhat hypothetically, that take form of inputs and feedback loops between sectoral policies" (Mass, 1991).

In the present context System Dynamics model based analysis is more relevant as M-Commerce and its growth is a function of enabling technologies, business and revenue models of the stakeholders, facilitating government policy frameworks and regulations.

Growth opportunities, strategies and sustainability issues in E-Commerce at firm level were discussed and analysed (Oliva et al., 2003) and for small and medium firms using System Dynamics models was looked at (Bianchi \& Bivona, 2002). Park and Ahn studied impact of self- regulation policy versus tax and rebate policy on online game addiction problems using System Dynamics models (Park \&Ahn. 2010). Study of influencing factors for mobile commerce market, mobile commerce diffusion and also strategic planning of mobile commerce terminal industry with specific reference to China using System Dynamic modelling approach was conducted by Wang and Cheong (Wang \& Cheong, 2005a, 2005b).Casey and Toyli evaluated the effect of technology harmonization and mobile number portability policies on mobile voice diffusion and service competition using system dynamics (Casey and Toyli, 2012). In the present paper the authors develop system dynamics simulation models to represent the interrelatedness and complexities of the M-Commerce eco-system and understand the impact of various regulatory and policy interventions on M-Commerce growth with specific reference to India. The objective of this work is to study the impact of facilitating policies on the extent of M-Commerce growth in India and also identify the critical policy area(s) for M-Commerce growth.

Section 2 of the paper elaborates the M-Commerce eco-system and regulatory and policy challenges in the Indian context in particular. Based on the policy evolution in telecommunications and E-Commerce, the policy design for M-Commerce is described and discussed in section 3. (Appendix 1 presents the major regulatory interventions that have taken place in India and their impact on the mobile industry). Section 3 also contains the causal loop diagram along with the stock \& flow diagram. Section 4 details the model, basic assumptions, scenarios generated and analyses of the results. (Appendix 2describes the policy factors and explains their status, which have been used to build the policy factor curves). Section 5 gives the summary and conclusions. 


\section{M-Commerce Ecosystem: Regulatory and Policy Challenges}

The M-Commerce ecosystem is influenced by policies and regulations that impact the stakeholders, in turn enabling healthy and fast growth of M-Commerce. However, M-Commerce is at a nascent stage in India poses challenges in the regulatory and policy domains. Services in M-Commerce are a convergence of services in mobile telecommunication industry and electronic commerce. Therefore, studying the factors and policies that have influenced the growth of mobile telecom and E-Commerce sectors/services will be helpful in understanding the desired policy interventions and their impact on M-Commerce.

\subsection{Regulatory Challenges}

The mobile telecom sector in India has been performing outstandingly well in last few years, due to a good regulatory system. However, the sectoral regulatory system that has evolved, in India, as a result of liberalization and privatization fails at many fronts to address the issues raised by convergence of technologies in both wired and wireless segments. With the advent of third generation technology in mobile communications facilitating internet access and commerce on mobile devices, the existing sectoral regulatory system needs some alterations. The regulatory governance in case of M-Commerce falls under the purview of numerous sectoral regulators. The regulatory gamut of various sectoral authorities in India such as the Reserve Bank of India (the Central Bank and financial regulator), Securities and Exchange Board of India (the Capital Market regulator), Ministry of Information and Broadcasting (content regulator), Telecom Regulatory Authority of India (Telecom and broadcasting carriage regulator), Ministry of Commerce\& Industry, Ministry of Communication \& IT, Competition Commission of India, The IT Commission, various utilities' regulators, taxation bodies are independent of each other. Independence and autonomy being considered as the prime factors behind their successful working, there are no coordination frameworks. Stakeholders in businesses based on new technologies such as M-Commerce would have to provide a range of services falling under the regulatory jurisdiction of multiple authorities. In the absence of coordination among various regulatory agencies, it is the industry which stands to lose. The situation is worsened in case of difference of opinion and interests among the regulators on any issue (Sharma, 2007).

There is an increasing inclination of businesses to diversify in unrelated areas, such as telecom companies into banking sector and broadcasting; white goods and infrastructure companies into telecom industry; power companies into the internet market; banking companies into the futures and commodity markets. This has not only increased competition among business entities but has also introduced competition among services and their delivery platforms. Thus horizontal expansion of business firms has further increased the need for integrated regulatory mechanisms and the regulatory responsibility of states to check any abuse of market power.

In addition, since the services provided in M-Commerce are integrated, the regulatory purview also needs to be under a single framework. A formal coordination mechanism has to be in place to coordinate different regulators of the M-Commerce eco-system. The regulatory system needs to be adapted to the new challenges to build the confidence of market, various stakeholders and ultimate users. Since M-Commerce is a convergence of Mobile telecommunications and E-Commerce, we outline the industry context in India and the policies that influenced the two industry verticals independently.

\subsection{Telecommunication Sector in India: Policy and Regulatory Interventions}

Telecom sector in India has been through two main phases of policy governance - The National Telecom Policy '94 which stressed the need for private sector investment in telecom and the National Telecom Policy '99 which introduced the revenue sharing mechanism of license fees. The third phase is expected with the introduction of $3 \mathrm{G}$ technology in mobile communications.

A set of appropriate regulatory policies have been instrumental in bringing the telecom revolution in India. The Telecom Regulatory Authority of India (TRAI) which is a national independent regulatory body was established in 1996. The major regulatory interventions were the introduction of WLL technology, tariff regulations, calling party regime, reduction in Access Deficit Charges, Universal Service Licensing and infrastructure support. TRAI interventions on tariff were a landmark, which brought down the service charges from INR 16 per minute to INR 7 per minute within a year, breaking an informal price cartel of the two major operators. Further enhancement in services and reduction in charges was facilitated by allowing competition in the telecom sector. Technology and service independent unified licensing regime and reduced regulatory charges further brought down service charges. The key regulatory interventions that have taken place in India and the impact of regulatory and policy changes on mobile industry subscriber base are given in Appendix 1 . 


\subsection{E-Commerce in India: Policy and Regulatory Interventions}

E-Commerce adoption rate in India has picked up due to increased penetration of internet and its usage for transactions. There were16.18 million internet subscribers, 8.71 million broadband subscribers and 177.87 million wireless data subscribers by March, 2010 (TRAI, 2010). The rising E-payment trends in India are mainly due to increase in financial card circulation from 51 million in 2004 to 240.2 million in 2009 (Euromonitor International, 2010).

Adoption of E-Commerce in business is an important indicator of economic growth. In India most of the activity is seen in the B2C segment as compared to developed countries, which see a high activity in B2B segment. The reason for this is lack of awareness among masses, the poor infrastructure support in terms of technology, transport, power, roads, bandwidth etc. (Vaithianathan, 2010;Purohit \& Purohit, 2005). The available internet connectivity in India is skewed towards urban areas depriving the population residing in rural areas from being a part of the e-revolution. The issue of E-Commerce and its regulations in India is therefore different compared to the developed nations. Hence, the policy framework in India should not only aim at an increase in internet based transactions but also aim for infrastructure development. In addition, the most sensitive issues of privacy, data protection and protection of consumer interests need to be handled on a priority basis in policy making to build consumer trust among the prospective users.

Various policy and regulatory attempts have been initiated of which The Information Technology Act 2000India is an important one. This act provides for legal recognition of communications and transactions carried out by means of electronic data interchange and other means of electronic communication. The act includes authorizing and certifying authorities for issuing digital signatures, penalties and adjudication in case of cyber-crimes and empowers the government to regulate these authorizing agencies and establishment of a Cyber Regulations Appellate Tribunal. India is the twelfth country in the world to devise and implement cyber laws (India Reports, 2009). It has provided a legal framework for smooth conduct of E-Commerce and its extension M-Commerce by tackling some of the major issues associated with E-Commerce requirements, such as, legal recognition for electronic messages, records and documents to be admitted as evidence in a court of law. However, the Act has failed to address the issues of protection for domain names, infringement of copyright laws, jurisdiction aspect of electronic contracts, taxation of goods and services traded through E-Commerce/M-Commerce and stamp duty aspect of electronic contracts.Besides these issues, M-Commerce transactions are more vulnerable to frauds as there is no record of the transaction made, either the devices need to be updated to have provision for same, or network needs to be updated with memory capacity. Else it needs to be mandated at the operator end to keep record of such transactions and reflect them in monthly bill. This serves limited purpose as not all transactions are made through operators. Such issues, which are peculiar to M-Commerce, make the role of policies and regulations imperative to take care of the stakeholder interests in the M-Commerce eco-system.

The stakeholders that have been identified in the M-Commerce domain are - Mobile Users, Content Providers, Application Developers/Aggregators, Retailers, Banks/Financial Institutions, Mobile Service Providers, Mobile Terminal Manufacturers and Government. The governance of the stakeholders, other than Mobile Users and Government fall under five major policy sectors namely, content policy, retail policy, banking policy, telecom policy, and mobile terminal industry policy. A detailed analysis of their interest with respect to each other reveals that there is conflict of interest on many issues among two or more stakeholders. Therefore, every stakeholder would try to use his bargaining power to his advantage. Hence the aim of regulatory authority should be to balance these conflicts in the best interest of the society (for details please see Sundar et al., 2006). For example while the Mobile Service Providers would seek minimum tariff regulations, the Government has to ensure reasonable pricing in the interest of Mobile Users. The telecom regulator in India had to intervene in 1999 to bring down the very high prices of mobile services. This triggered adoption of mobile services and thus industry growth (see Appendix 1).

\section{Policies and Their Impact on M-Commerce}

In general, trends from matured markets can be taken as reference (Pedersen et al., 2003) but cannot be applied directly to India due to differences in socio-economic settings, culture and demographics.

M-Commerce has to be regulated mainly on three fronts, namely, legal, economic and social. Under the rubric of legal framework there are a number of factors like laws, regulations, acts, treaties that should be India specific and suitable to the local needs apart from being compatible with international norms and practices. Under economic regulations fall the rules for operating agencies and individuals, whereas the social regulations are concerned with content regulations like type of content allowed, gaming laws etc. For proper development of 
M-Commerce, prevalence of a sound policy support and a legal M-enabling environment is a must. These should provide for:

- Common minimal set of standards and codes of conduct for service/application providers, network providers and equipment manufacturers

- Regulations to ensure healthy competition in the markets

- Define scope of M-Commerce and associated details like acceptance of m-contracts etc.

- Details on domain name registration

- Ensure Network and information security

- Content Regulation

- User Data Protection

- Consumer protection and privacy

- Intellectual Property Rights

- Regulations on M-banking and M-payments like licenses to provide financial services, security of mobile transactions, standards on protocols and equipment used and security features built in them etc.

- Duties and Taxation laws for mobile enabled business

- Dispute settlement Mechanism

- Cyber crimes including fraud, forgery, misuse of content etc. in m-domain.

The above can be classified under aforementioned five policy sectors namely Banking, Content, Retail, Mobile and Mobile Terminal manufacturing Policy sectors. The policies in these policy sectors are governed by the government as a stakeholder in the M-Commerce ecosystem. The stake holders affected by the policies in each policy sectorare:

1) Banking Policy Sector: governs banks/financial institutions and the mobile service providers

2) Content Policy Sector: governs the content providers, application developers/aggregators, mobile service providers

3) Retail Policy Sector: governs the retailers, mobile service providers, banks/financial institutions

4) Mobile Telecommunications Policy Sector: governs the mobile service providers

5) Mobile Terminal Manufacturing Policy Sector: governs the mobile terminal manufacturers

Over and above these policy sectors and the stakeholders affected by them, mobile users also affect the M-Commerce ecosystem as a primary stakeholder. User perception and hence adoption of M-Commerce services would be primarily influenced by facilitating conditions such as affordability, availability of services, ease of subscription and behavioural intentions such as perceived usefulness, perceived value derived, ease of use, and social influence (Venkatesh et al., 2003).

Policies in above identified sectors are still evolving to meet the needs of M-Commerce and therefore it is difficult to give accurate predictions of the course of these policies in time. It is also difficult to predict and measure these variables quantitatively. The cause and effect relationships between and among all the stakeholders of the M-Commerce eco-system are complex and dynamic in nature and hence difficult to understand. In order to study and evaluate the impact of various policy interventions on the growth of M-Commerce, simulation models based on a systems dynamics (SD) approach have been developed in this paper. This is achieved by identifying stakeholders, the respective governing policy sectors, and various policy factors representing the favourability status of policies in these sectors. The interrelationships and causality at policy sector and policy factors level is modeled to reflect the stakeholder interests. In designing the SD model for M-Commerce, policies in the M-Commerce ecosystem have been represented by the five policy sectors, as discussed above and shown in Figure 1.

The SD model developed in this paper is of Type 2 with reference to Mass's classification (Mass, 1991). There is no preceding work and little data or literature available in this domain of policy impact on M-Commerce, in particular-with specific reference to India. Information and data from various secondary sources, viz., market reports, regulators' reports and analysts' reports were used to gain insights into the evolving environment in M-Commerce domain in India. This helped in the identification of stakeholders, relevant policy sectors and sector specific policy factors (policy levers) and their inter-dependencies in M-Commerce domain. Taking this 
as the basis, the casual loop diagram and the base model were developed (Mohapatra et al., 1994; Sterman, 2000). In the absence of numerical time series data for the input variables in the model, best guesses must be substituted (Forrester, 1996).

In the presented work, based on the secondary data, experts' inputs, current policy and regulatory initiatives in India and anticipated trends in policy and business environment the input data for the model was defined. Importing data from experiences of other countries was not considered appropriate as it is not directly applicable in the present Indian context and would lead to ambiguity (Mass, 1991).

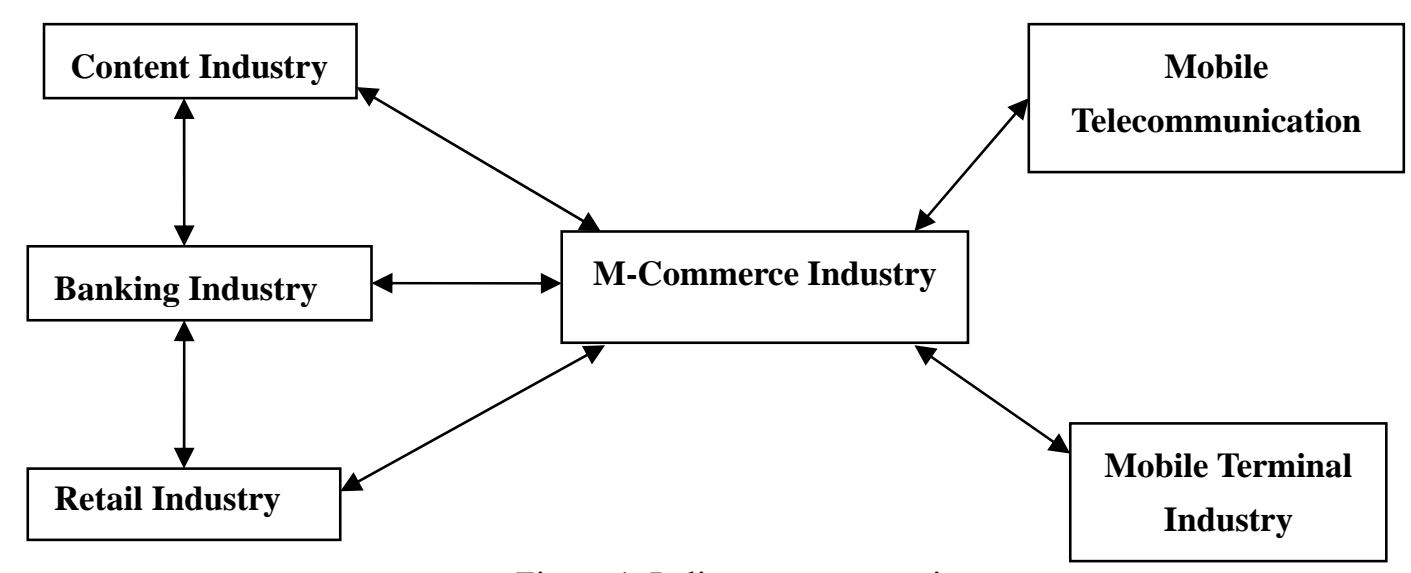

Figure 1. Policy sectors overview

The stakeholder identification, causality and overall structure of the model were validated using semi-structured interviews with experts, viz., regulators (Note 1), public service provider (Note 2), E-Government policy makers (Note 3) (Sharma, 2007). Thereafter, different scenarios were generated to identify the influence of policy factors under various conditions.

\section{Causal Loop Diagram and Model Description for the M-Commerce Eco-system}

The Causal Loop Diagram in Figure 2 represents the cause and effect relationships for the M-Commerce ecosystem described above. These causal loops form the basis for developing the simulation model.

Any positive policy initiative that results in the growth of M- commerce in the identified five sectors will have a positive impact on the growth of M-Commerce. Favorable banking policies are primary to the development of retail and content industry as the sale of content, goods, services in retail industry through mobile devices would largely depend on payment facilitation through banks. For this, banking policies with respect to payment mechanisms, technology and protocol standards for M-banking and M-payments, guidelines to ensure security of data and privacy of the users for all transactions through mobile have to be in place. In the absence of these, widespread sale of content, goods and services through mobile handheld devices cannot take place (Kruger, 2001; Bank for International Settlement, 2003). Absence of conducive banking policies will make retail and content related policy initiatives redundant and favorable banking policies will positively impact both the content and retail policies as well. Increase in M-Commerce users will in turn accelerate the government's initiatives in framing enabling regulations and policies to facilitate a healthy business environment.

The potential M-Commerce Users seen in the causal loop diagram are defined as the difference between the number of mobile subscribers and M-Commerce users at any given time. The mobile subscriber projections are available and take into account various demand drivers, such as, rapidly increasing coverage, declining handset prices and tariffs, increasing trend of multiple subscriptions by users and increasing adoption of mobile services (TRAI, 2010; CRISINFAC, 2010a). These projected numbers of mobile subscribers are used as an input to the model. Initially the number of potential M-Commerce users is high due to the number of mobile users being high and the number of M-commerce users being low. Thereafter, as M-Commerce picks up this gap reduces and the potential M-commerce user pool declines, which is the balancing loop in the model.

The policy sectors identified above will be influenced by a host of policy factors, which are the levers in making the respective policy sectors conducive for M-Commerce growth. Nineteen such policy factors have been identified. The details of the policy factors and the policy sector(s) they influence are given in Table 1. The table also details the governed stakeholders for each policy sector. Some of the important policy factors occur in 
multiple sectors. These common elements are the breeding grounds of stakeholder conflicts due to differing interests. For example, RSMPF will be influenced in different directions by mobile operators and content providers/aggregators. Regulator's role is prominent in balancing this conflict of interest among stake holders. The overall policy favourability of a specific sector is determined by a combination of these policy factors and referred to as Policy Favourability Indicator for the specific sector, namely, Banking Policy Favourability Indicator, Content Policy Favourability Indicator, Retail Policy Favourability Indicator, Mobile Policy Favourability Indicator and MTI Policy Favourability Indicator.

Table 1 also details the governing agencies/actors that influence, design and operate these policy sectors' levers. For example, Banking sector policy levers lie in the hands of Ministry of Finance, Central Bank- Reserve Bank of India, TRAI and Ministry of Law. The Content sector policies are mainly controlled by Ministry of Communications \& IT, TRAI, Ministry of Law, Central Bank-Reserve Bank of India, Ministry of Information and Broadcasting and Ministry of Commerce \& Industry.

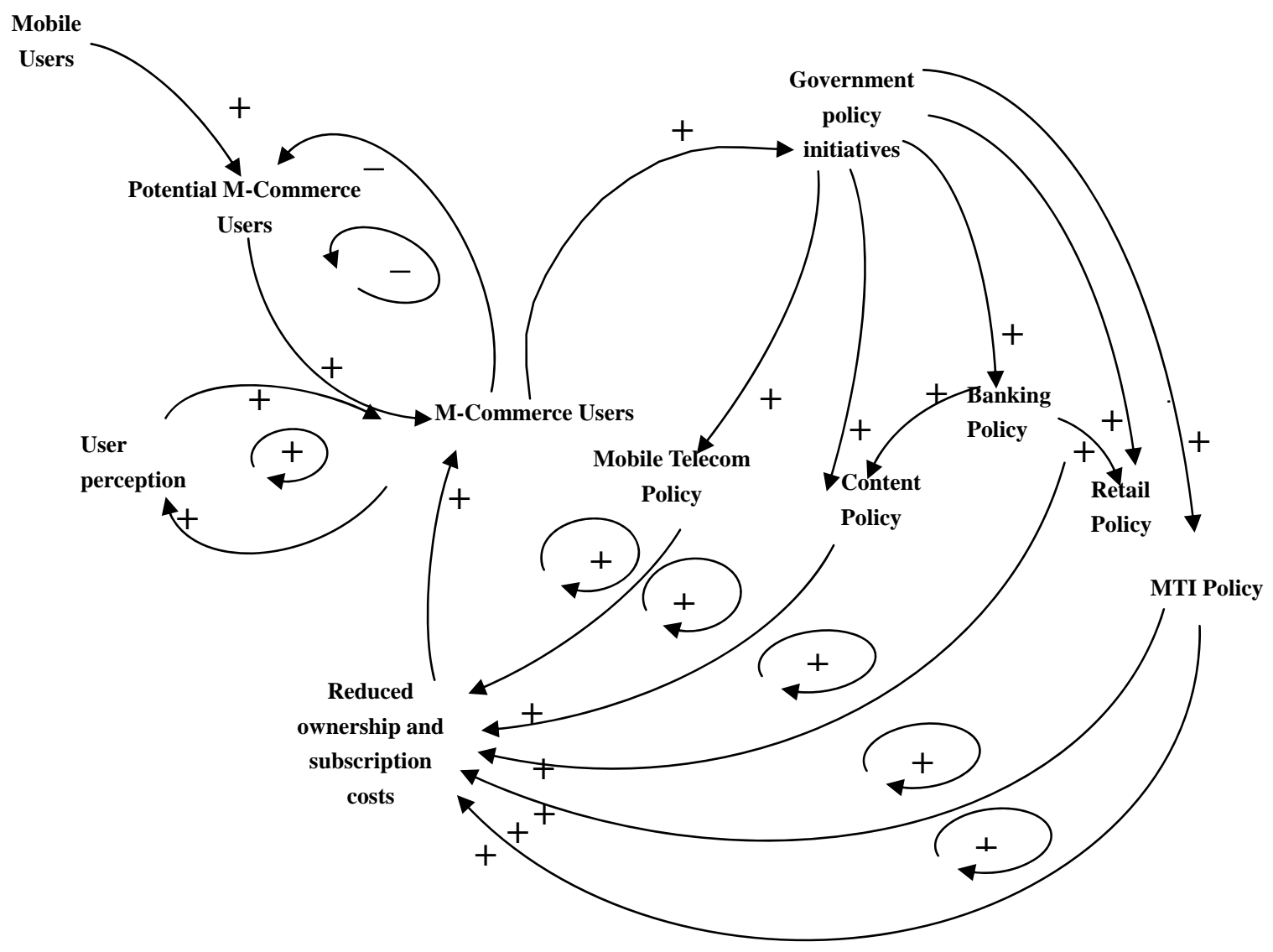

Figure 2. Overall causal loop diagram for policy design in M-Commerce

Figure 3 is the Stock and Flow diagram for the model. The policy factors for each sector cumulatively determine the Policy Favourability Indicator for that specific sector. This in turn determines the policy environment for the specific sector which is represented as a stock in the model and Figure 3. A stock valuecloser to one indicates a positive environment of the specific sector for M-Commerce. The five policy environment stocks determine the policy favourability for M-Commerce referred to as the 'M-Commerce Favourability Indicator'. The value of this indicator is the weighted average of the five policyenvironment levelsand lies between 0 and 1 .

It has been assumed that the potential M-Commerce user pool comes from the mobile subscriber base, as any user who desires to use M-Commerce services has to first become a mobile subscriber. Based on the facilitating policy environment and user perception,some of the Potential Mobile Commerce Users would actually subscribe to various M-Commerce services. Thus the addition to M-Commerce users in any given year is a function of Potential Mobile Commerce Users, M-Commerce Favourability Indicator and User Perception. 
Policies addressing mobile telephony sector such as spectrum allocation, legal environment, reduced duties, infrastructure support, reduced taxes and regulatory charges, dispute settlement mechanisms, laws facilitating fair competition and facilitating norms for foreign investments will bring down the cost of mobile connectivity to mobile users. Similarly, for Mobile Terminal manufacturing industry, policy support in the areas of spectrum allocation, reduced import duties, infrastructure support, reduced taxes, availability of technical manpower, facilitating labor and investment laws will reduce the production and hence, handset costs. Policies relating to banking code, micro finance, security and privacy of users and data, fair revenue sharing arrangements, facilitating legal environment and payment mechanisms would build confidence in users and influence increased purchase/subscribe content, goods or services through mobile delivery platform. Similarly, appropriate policy measures in the content and retail sectors addressing revenue sharing mechanisms, legal environment, payment mechanisms, content code and gaming regulations, reduced duties/taxes, organized retail and technical manpower availability will boost these sectors and in turn boost M-Commerce growth.

Table 1. Policy sectors in M-Commerce ecosystem, related stakeholders and their influencing policy factors

\begin{tabular}{|c|c|c|c|c|c|c|}
\hline $\begin{array}{c}\text { Policy } \\
\text { SectorsPolicy } \\
\text { Factors }\end{array}$ & $\begin{array}{c}\text { Banking } \\
\text { Policy }\end{array}$ & $\begin{array}{c}\text { Content } \\
\text { Policy }\end{array}$ & RetailPolicy & $\begin{array}{c}\text { Mobile } \\
\text { Telecom } \\
\text { Policy }\end{array}$ & $\begin{array}{c}\text { Mobile } \\
\text { Terminal } \\
\text { Policy }\end{array}$ & $\begin{array}{c}\text { Policy } \\
\text { GoverningAgencies/ } \\
\text { Actors }\end{array}$ \\
\hline $\begin{array}{c}\text { Spectrum } \\
\text { Allocation (SAPF) }\end{array}$ & & $\sqrt{ }$ & & $\sqrt{ }$ & $\sqrt{ }$ & $\begin{array}{c}\text { Ministry of } \\
\text { Communications \&IT }\end{array}$ \\
\hline $\begin{array}{l}\text { Banking Code } \\
\text { (BCPF) }\end{array}$ & $\sqrt{ }$ & & & & & Ministry of Finance \\
\hline $\begin{array}{l}\text { Micro Finance } \\
\text { (MFPF) }\end{array}$ & $\sqrt{ }$ & & & & & Ministry of Finance \\
\hline $\begin{array}{c}\text { Security and } \\
\text { Privacy (SPPF) }\end{array}$ & $\sqrt{ }$ & & & & & $\begin{array}{c}\text { Ministry of Finance; } \\
\text { Central Bank- Reserve } \\
\text { Bank of India }\end{array}$ \\
\hline \multicolumn{7}{|l|}{ Revenue Sharing } \\
\hline $\begin{array}{l}\text { Mechanism } \\
\text { (RSMPF) }\end{array}$ & $\sqrt{ }$ & $\sqrt{ }$ & $\sqrt{ }$ & $\sqrt{ }$ & & TRAI \\
\hline $\begin{array}{l}\text { Legal Environment } \\
\text { (LEPF) }\end{array}$ & $\sqrt{ }$ & $\sqrt{ }$ & $\sqrt{ }$ & $\sqrt{ }$ & & Ministry of Law \\
\hline $\begin{array}{l}\text { Payment } \\
\text { Mechanism } \\
\text { (PMPF) }\end{array}$ & $\sqrt{ }$ & $\sqrt{ }$ & $\sqrt{ }$ & & & $\begin{array}{c}\text { Central Bank- Reserve } \\
\text { Bank of India }\end{array}$ \\
\hline $\begin{array}{l}\text { Content } \\
\text { Availability } \\
\text { (CAPF) }\end{array}$ & & $\sqrt{ }$ & & & & $\begin{array}{l}\text { Ministry of Info. } \\
\text { \&Broadcasting }\end{array}$ \\
\hline $\begin{array}{l}\text { Gaming } \\
\text { Regulations } \\
\text { (GRPF) }\end{array}$ & & $\sqrt{ }$ & & & & $\begin{array}{c}\text { Ministry of Info. } \\
\text { \&Broadcasting }\end{array}$ \\
\hline $\begin{array}{l}\text { Import Duty } \\
\text { (IDPF) }\end{array}$ & & $\sqrt{ }$ & & $\sqrt{ }$ & $\sqrt{ }$ & $\begin{array}{l}\text { Ministry of Com. \& } \\
\text { Industry }\end{array}$ \\
\hline Retail (RePF) & & & $\sqrt{ }$ & & & $\begin{array}{l}\text { Ministry of Com. \& } \\
\text { Industry }\end{array}$ \\
\hline $\begin{array}{c}\text { Infrastructure } \\
\text { Support (ISPF) }\end{array}$ & & & & $\sqrt{ }$ & $\sqrt{ }$ & $\begin{array}{l}\text { Ministry of Com. \& } \\
\text { Industry }\end{array}$ \\
\hline Taxation (TPF) & & & $\sqrt{ }$ & $\sqrt{ }$ & $\sqrt{ }$ & $\begin{array}{l}\text { Ministry of Com. \& } \\
\text { Industry }\end{array}$ \\
\hline $\begin{array}{c}\text { Regulatory } \\
\text { Charges (RCPF) }\end{array}$ & & & & $\sqrt{ }$ & & $\begin{array}{c}\text { Ministry of } \\
\text { Communications \&IT }\end{array}$ \\
\hline Dispute Settlement & & & & & & \\
\hline $\begin{array}{l}\text { Mechanism } \\
\text { (DSMPF) }\end{array}$ & & & & $\sqrt{ }$ & & TRAI \\
\hline $\begin{array}{c}\text { Competition } \\
(\mathbf{C o P F})\end{array}$ & & & & $\sqrt{ }$ & & $\begin{array}{c}\text { Competition } \\
\text { Commission of India }\end{array}$ \\
\hline
\end{tabular}




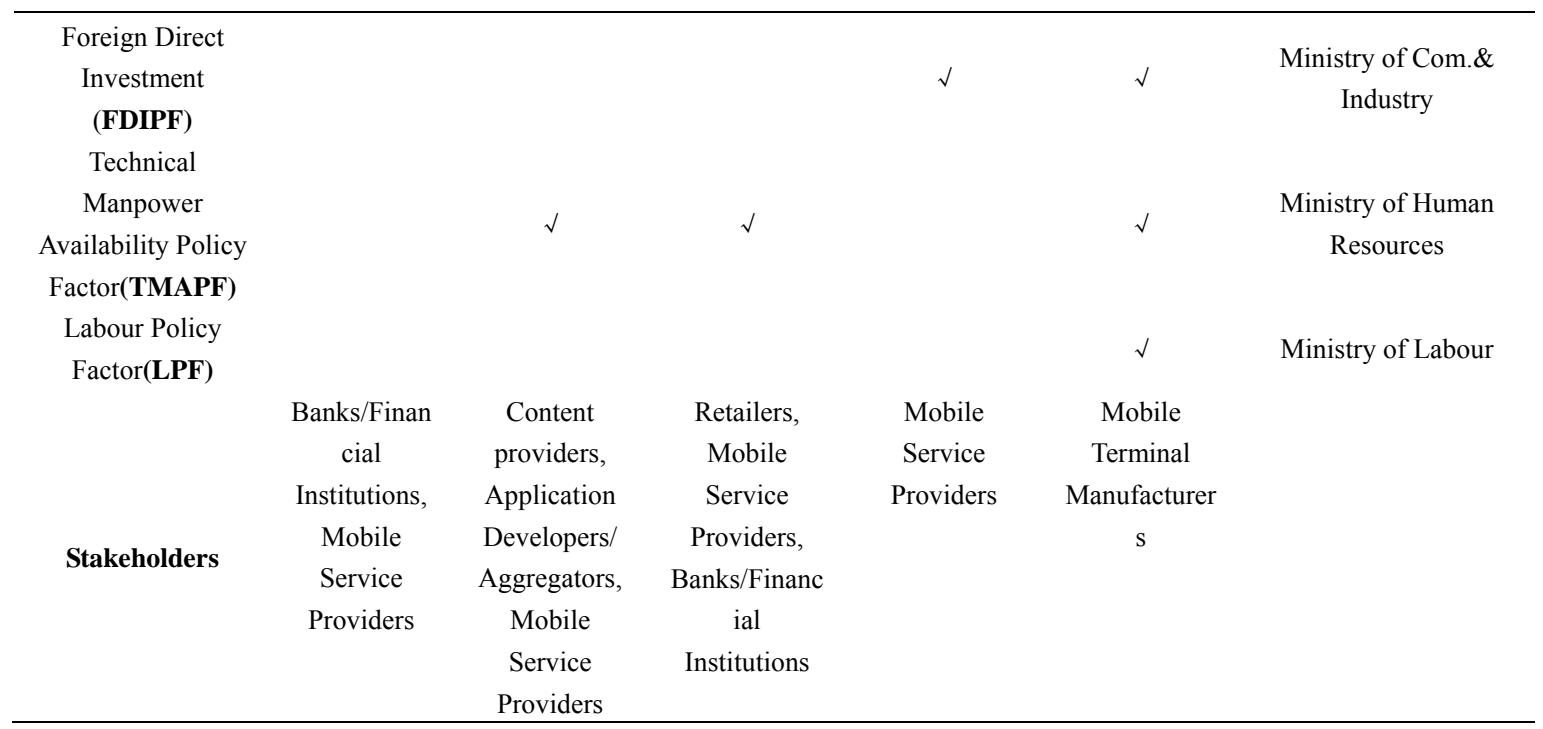

The model summarily incorporates all the policy factors encompassing the policy sectors and stakeholders. The five policy sectors are represented as five subsystems in the model. Details of the past and current status of the individual policy factors are given in Appendix 2 along with the anticipated future trends for the period under study, i.e., 2003-04 to 2013-14. Based on these observations, values of individual policy factors are arrived at on a scale of 0 to 1 as specified in Appendix 2. Values of several individual policy factors trace a non-linear path over this range.

The values of the nineteen individual policy factors specific to the respective sectors are aggregated to determine the value (on a scale of 0 to 1 ) of sector specific Policy Favourability Indicator, namely, banking, retail, content, mobile telecommunication and mobile terminal industry sectors.

The users' preferences play a significant role in determining whether a mobile subscriber is converted as M-Commerce user. The user attitudes towards adoption of new technology have been explained using various perspectives i.e., psychology, motivation literature, behavioral sciences. The theory of Reasoned Action, theory of Planned Behavior, Technology Acceptance Model, Motivational theory, Unified Technology Acceptance model have been used by researchers to empirically test the individual acceptance of new technology.

The user attitudes towards a new technology largely depend on the perceived usefulness, ease of use, perceived value derived, social pressure, affects like joy, elation towards use, and the facilitating environmental conditions (Venkateshet al, 2003). The User Perception is also taken to vary on a scale of $0-1$.The M-Commerce Favourability Indicatorand the User Perception are aggregated to determine the extent of Potential M-Commerce users translating to M-Commerce users. This aggregation model is presented in Figure 4. The SD model in the paper is based on this aggregation model. 


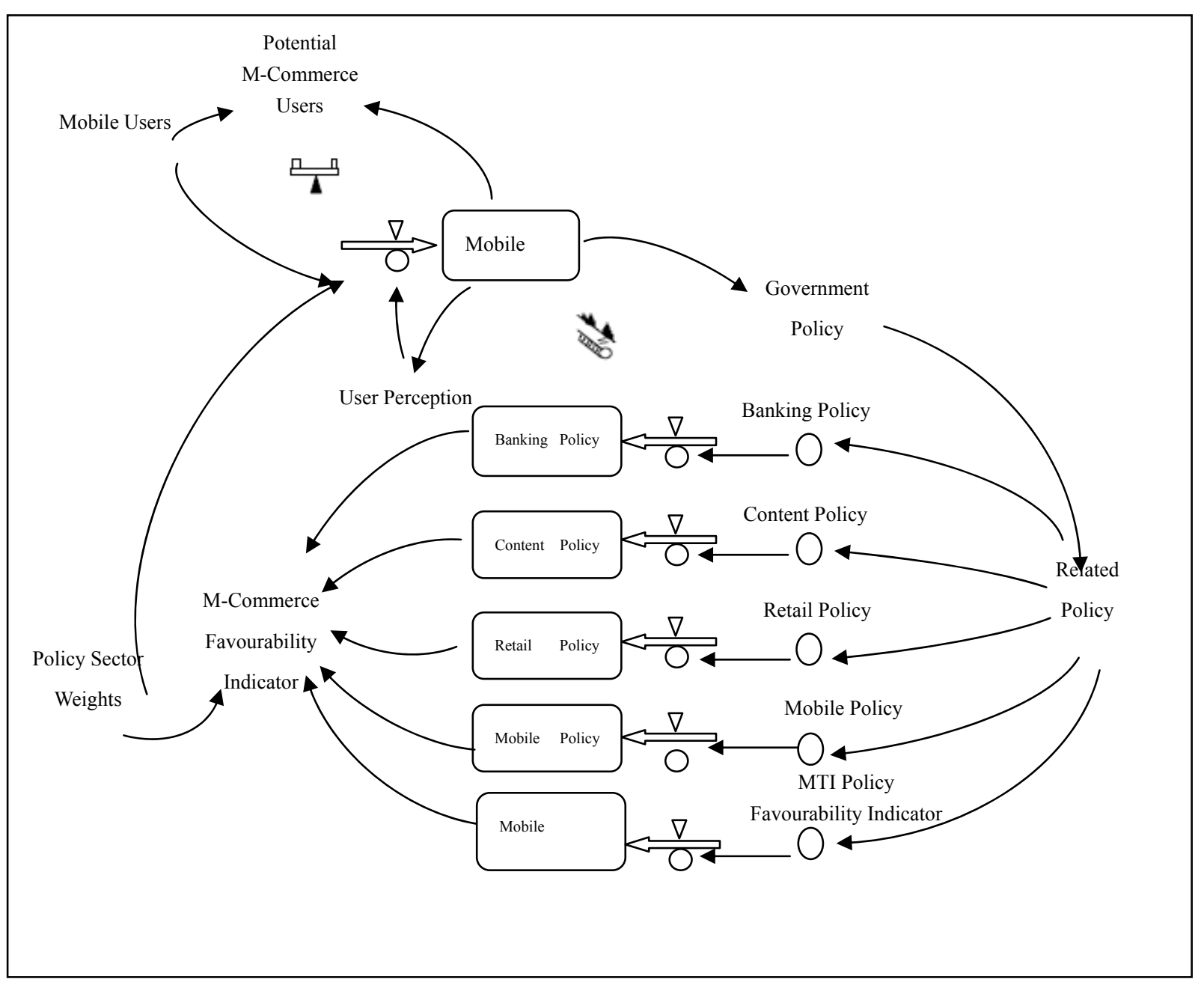

Figure 3. Stock and flow diagram 


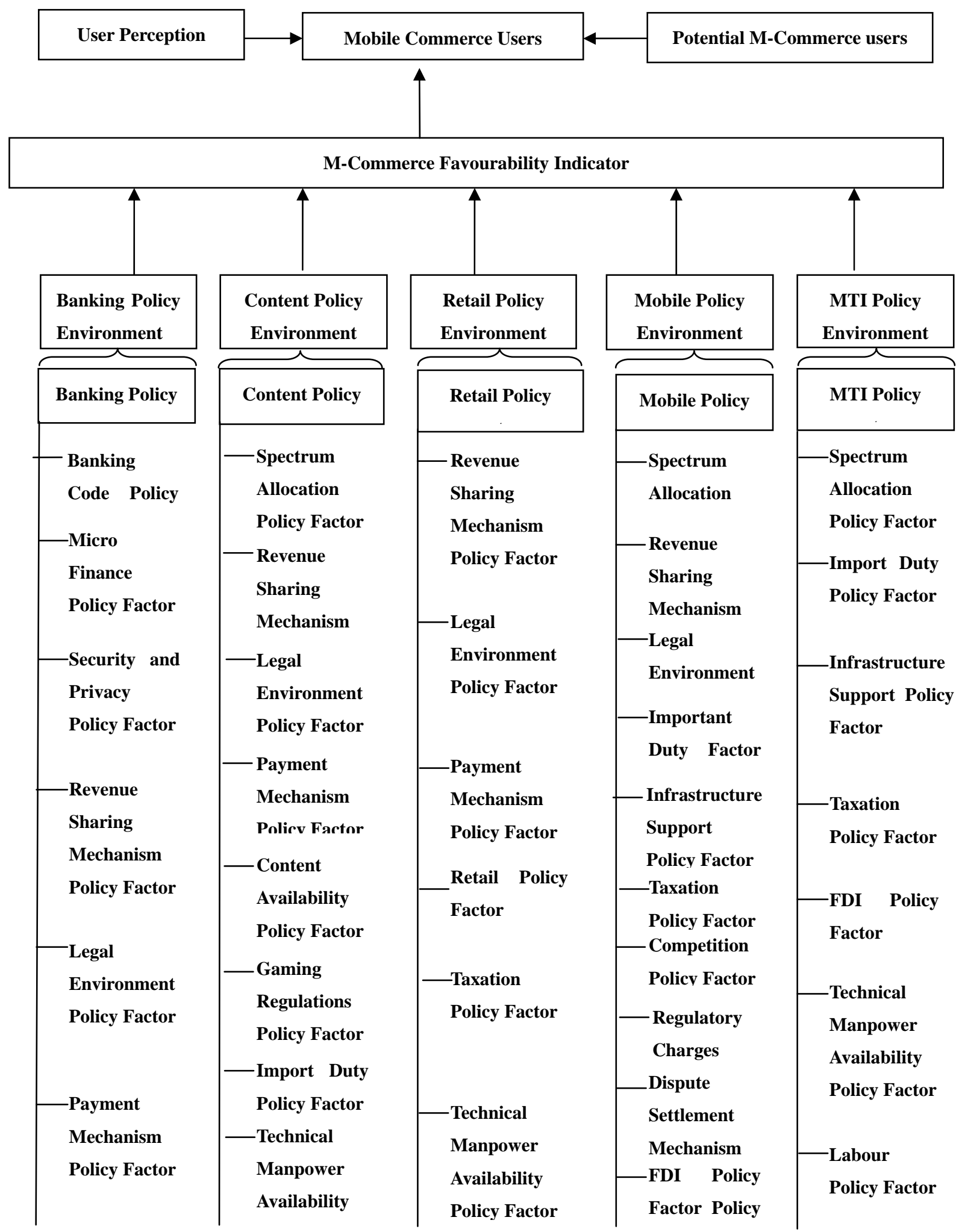

Figure 4. Aggregation model for M-Commerce favourability indicator \& user perception 


\section{Simulating the M-Commerce Eco-System}

The simulations are carried out and the value of the M-Commerce Favourability Indicator and the number of M-Commerce Users are observed as outputs for a period of eleven years starting from 2003-2004 till 2013-14. This period is considered appropriate as in India, basic M-Commerce services started taking off from the year 2003-04 and are likely to mature by 2013-14. It is expected that during the period 2009-10 to 2013-14policies in the M-Commerce domain will mature to foster the growth of M-Commerce. This corroborates with the experiences in mobile telecom industry where the last five years have witnessed a promising policy environment (TRAI, 2005 a, 2005b, 2006, 2007, 2008 \&2009; CRISINFAC 2006; 2007a, 2007b, 2007c, 2008, \& 2010a). There has been a tremendous rise in mobile subscriber base, which is growing at the rate of over 14 million subscribers a month (TRAI, 2010). The public sector mobile operators, i.e., MTNL and BSNL launched 3G enabled value added services in 2009 triggered uptake of VAS. In addition, with Indian government concluding the $3 \mathrm{G}$ spectrum auctions recently, i.e. in May 2010, the private operators will start rolling out $3 \mathrm{G}$ services shortly.

The number of mobile subscribers during this 11 year period has been taken as reported and predicted by TRAI (TRAI, 2005b, 2010) and CRISINFAC (CRISINFAC, 2010a). Entry of 3G services which facilitate high-speed data access on wireless networks shall necessitate accelerated policy guidelines from government as in any other upcoming technology or industry. The number of mobile subscribers in 2003-04 was 33.6 million (TRAI, 2005b). The initial number of M-Commerce users is taken to be a conservative $2 \%$ of the mobile subscribers, which had been suggested by experts.

The individual policy factors affecting each policy sector are assigned equal weights in determining sector specific policy favourability indicator. The policy factor values outlined in Appendix 2 are used as inputs. Simulations are also run using values for the policy factors obtained from domain experts as inputs. Some individual policy factors, such as revenue sharing mechanism, legal environment, payment mechanisms gets reinforced by their presence in more than one policy sectors in the model. The combined effect of the sector policy favourability indicators is defined as the M-Commerce Favourability Indicatorwhose value will vary between 0 and 1 . Values close to 1 will imply that policies are favorable so that a larger fraction of mobile subscribers will convert to M-Commerce users.

User Perception is defined as the ratio of M-Commerce Users to Mobile subscribers. High values for User Perception indicate higher user acceptability and would result in a faster conversion of the mobile subscribers to M-Commerce users. A User Perception value of 1 would imply the extreme possible case where all mobile subscribers become M-Commerce users. The conversion of Potential M-Commerce Users to M-Commerce Usersis determined by a weighted average of M-Commerce Favourability Indicator and User Perception. The values for these weights are taken to be 60:40 for the base model. Subsequently various scenarios are simulated with different relative weights, viz., 20: 80 and 80:20.

The number of M-Commerce Users in each year is observed as an output. The other observed outputs are the values of the M-Commerce Favourability Indicator, User Perception and the M-Commerce User Growth defined as addition in M-Commerce users every year. The simulations are carried out using the System Dynamics simulation software "iThink" (version 9.1, iseesystems, inc.,2008).

\subsection{Assumptions for the Base Model}

The inputs for the base model for the period under study (2003-04 to 2013-14) are taken to be as follows:

The number of mobile subscribers is taken from TRAI, CRISNFAC reports. The initial number of M-Commerce users is $2 \%$ of the mobile subscribers.

The individual policy factor values have been taken in the range of $0-1$ based on available information and our understanding as detailed in Appendix 2.

Equal weights are assigned to each of these individual policy factors. The five sector specific policy favourability indicatorsare determined using these inputs. The M-Commerce Favourability Indicatoris determined using equal weights for these five sector specific policy favourability indicators.

User Perception is taken to be the ratio of M-Commerce Users to Mobile subscribers at any given time. The base model uses the M-Commerce Favourability Indicatorand User Perception values inthe ratio 60:40 to give the value of M-Commerce users at any given time. 


\subsection{Simulation Results of Base Model}

The results of the simulation for the base model with the assumptions stated above are given in Figure 5.

Outputs of the base simulation model as given in figure 5 represent M-Commerce users, M-Commerce Users' Growth (addition in M-Commerce users every year), User Perception and M-Commerce Favourability Indicator. The number of M-Commerce users is expected to be 771 million in the year 2013-14 which is 90 percent of the 860 million mobile users in 2013-14. The User Perception value increases from 0.02 in 2003-04 to 0.9 in 2013-14. The value of M-Commerce Favourability Indicator in 2013-14 is 0.78 indicating a favorable policy environment.

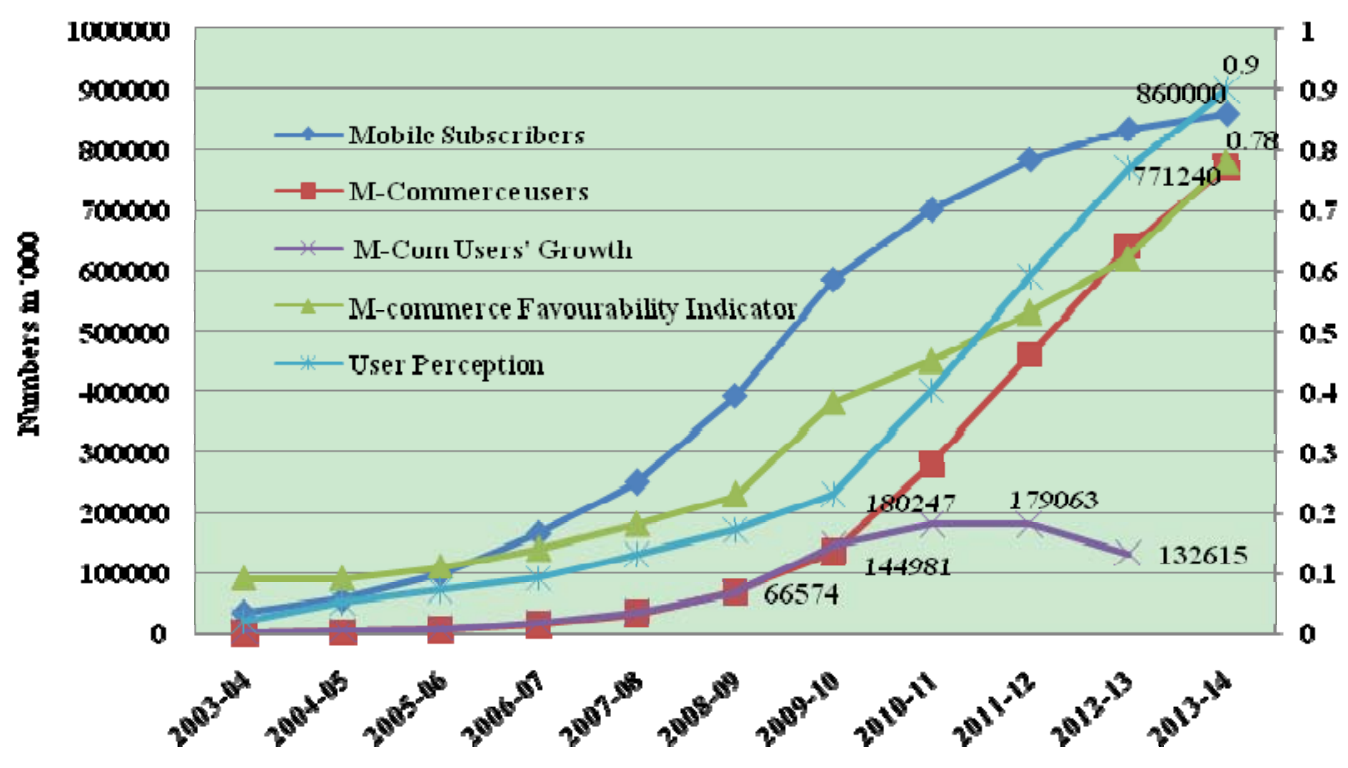

Figure 5. Base model simulation results

The possible reasons behind the slow growth of M-Commerce in the initial three years, that is, the first phase, are:

Limitations posed by then existing technology for offering high end services as only $2 \mathrm{G}$ technology was available in the market which had limitations on data transfer speeds.

Even simple payment related mechanisms, which are the essence of M-Commerce, were not in place, and business was limited to SMS, caller tune downloads.

Availability of M-Commerce compatible content was limited. The M-Commerce industry is largely content dependent and content push was limited to ring-tones, wallpapers and simple games, primarily due to technology $(2 \mathrm{G})$ bottleneck.

User acceptance is another important factor since a time lag is expected between technology introduction and adoption.

As customers are price sensitive and mobile users' market is not saturated, focus is still on customer acquisition for mobile telephony services. India being the lowest tariff regime in the world, mobile operators' focus is on increasing the customer base to address volume economies rather than creating awareness and educating the customers on M-Commerce services.

The M-Commerce Favourability Indicatorfollows a slow growth pattern in the initial years. This is expected as the pressure on regulatory and policy framing agencies is low given the not so significant M-Commerce users base. Similarly, the User perception is also seen to be low in the initial years. This can be explained by the Diffusion of Innovation Theory (Rogers, 1983) as it takes time for any technology to diffuse to critical mass beyond which the diffusion is self-driven.

Some reasons forthe accelerated growth in M-Commerce Usersin the second phase and the subsequent peaking 
phenomena, that is, the third phase, are:

Introduction of mandatory Mobile number portability (MNP by Ministry of Telecommunications, Government of India

Release of Central Bank (Reserve Bank of India) guidelines on mobile banking that include mobile payments, encryption and transaction security in June, 2008.

Release of 3G-spectrum policy in August 2008 and of 3G-spectrum for mobile operations in 2009-10 by Ministry of Communications and IT opened up the market for 3G technology-based services.

Allocation of $3 \mathrm{G}$-spectrum and launch of $3 \mathrm{G}$ enabled value added services by the public sector mobile operators, i.e., MTNL and BSNL in 2009.

$3 \mathrm{G}$-spectrum auction for private mobile operators in 2010.

Multitude of players in mobile content value chain (content/application owners, aggregators, software developers and technology enablers) resulting in increased mobile content availability.

Regulatory reforms that enable entry of new operators and technologies such as MVNO (Mobile Virtual Network Operators), and VoIP (voice over IP).

Regulatory interventions in revenue sharing mechanisms and payment mechanisms.

The above initiatives have been incorporated in the individual policy factors and are reflected by their increased values as explained in Appendix 2.

The overall picture of the simulation output with reference to M-Commerce user growth resembles a typical (new) product life cycle. While it is slow in the beginning, the M-Commerce Users' growth is accelerated in the second phase from 18 million new users added in 2006-07 to 145million in 2009-10. The growth peaks between 2010 and 2012 beyond which it slows down. This is because the addressable population is limited and the potential mobile commerce user pool reduces as more and more mobile users convert to M-Commerce users. The addressable population for mobile telephone subscriptions in India is approximately $60 \%$ of the total population, taking into account the population falling below poverty line and children under 14 years of age. The addressable tele-density is expected to be $70 \%$ of the addressable population by 2012 (CRISINFAC, Nov. 2007).

In the model Potential M-Commerce users are modeled as the difference of Mobile Users and M-Commerce Users. As explained above, with time the rate of increase of Mobile Users falls behind that of M-Commerce Users, which feeds back in the form of decline in the Potential M-Commerce user pool. The peaking of M-Commerce Users takes placewhen the increase in M-Commerce users surpasses the increase in Mobile Users. Given that the number of M-Commerce Users added in the model is a function of Potential Mobile Commerce users, User Perception and the M-Commerce Favourability Indicator, growth in M-Commerce Users slows down after reaching the peak.

The model indicates stabilization of growth and conversion of Mobile Users to M-Commerce users, near saturation of User Perception (0.9) and a stable policy environment (0.78) by 2013-14. Thus, M-Commerce is expected to reach substantial maturity in Indiaby year 2014. In the absence of a new technology paradigm, further growth in the mobile subscribers and in turn M-Commerce users would continue at a marginal level. M-Commerce growth will come from existing users adopting higher end value added services resulting in M-Commerce services.

M-Commerce in India will be at mature levels by 2013-14 indicated by the simulation results, provided appropriate policy and regulatory impetus is in place as anticipated and described in Appendix 2. Any changes or delays in one or more of the policies and regulatory initiatives are likely to impact the M-Commerce in India. Some of the possible scenarios described below have been simulated to understand the impact. 


\subsection{Model Validation}

The model validation process depends on the purpose and objective of the model (Barlas, 1996 and Mohapatra et al. 1994). When the purposeof the model is essentially a non-technical, informal and qualitative process the validation processes would have informal, subjective and qualitative components (Barlas, 1996). The purpose of the SD model in this paper is to understand the impact of policy and regulatory initiatives on the growth of M-Commerce in India and the structure has been built keeping this purpose in mind. Theconceptualization of the model proposedis based on a thorough understanding of the E-Commerce eco-system and its key players and the policy factors that affect its growth. Structural validation of the model is based on extensive use of existing industry reports during the model building phase and expert reviews after the modeling process.

Numerical confirmation of thepolicy factor values, is based on an in depth study of the available information in existing industry reports. This serves as the direct structure test (Barlas, 1996) for the model in this paper.

Behavior-reproduction test has been applied to validate the model behavior in the past years. Since there are no industry reports/ studies that indicate the number of M-Commerce users in India, for model's behavioral validation, the ratio of Value Added Services (VAS) contribution to total revenues of mobile telecom industry is considered as the most appropriate surrogate for the ratio of M-Commerce users to mobile users. As per COAI annual report 2007, the VAS component in total revenues of mobile operators had continuously increased from $7 \%$ (2003-04) to $9 \%$ (2004-05) to $12 \%$ in year 2005-06 (COAI, 2007).Similarly, the base model simulation results also show a continuous growth of 2\% (2003-04), 7\% (2004-05) and 9\% (2005-06), 12\% (2006-07) for M-Commerce users. For the period of 2008-2010, the VAS component in total revenues continued to grow despite significant drop in the tariffs (COAI 2010) which indicates continuous growth in M-Commerce users during this period as well. The base model simulation results for this period also reflect a continuous growth phase for M-Commerce users as seen in Figure 5.The initial values of M-Commerce users, i.e., for the year 2003-04, were taken as per expert opinion which explains the disparity in M-Commerce users for the initial year(s). This initial disparity is not of concern since the model equilibrium is independent of the initial conditions for given policies and exogenous inputs (Mass, 1991).

Behaviour prediction tests call for pattern prediction rather than point prediction. The M-Commerce growth seen from the simulation results for the base case follow an expected pattern of slow growth initially, followed by faster growth during the phase towards maturity and finally retardation as maturity is reached. The model was also tested for changed behaviour prediction by delaying the policy initiatives by one, two and three years. The behaviour is judged to be plausible under these conditions as described in section 4.4.1 below.

\subsection{Scenario Simulations}

\subsubsection{Scenario 1: All Policy Efforts Delayed in Time}

The results indicated by the base simulation can be tested for delays in regulatory initiatives and policy implementations. Scenario 1 simulates the effect of time delays in all five sectors defined for M-Commerce growth. For executing this all the five Policy Favourability Indicators were simultaneously delayed by one, two and three years. This essentially amounts to delaying all the 19 individual policy factors. The results obtained are given in Figure 6.

The simulations incorporating delay by one year indicate the number of M-Commerce users in 2013-14 being 725 million as compared to 771 million for the base case, which is around $6 \%$ less. The effect of a two-year delay in policy efforts results in a drop in M-Commerce users by 114 million that is around $14.8 \%$. The impact of delays by 3 years on M-Commerce users is even more significant with a decline by 204 million users, which is $26 \%$ reduction. This validates the basic premise of the study that timely policy actions are necessary to tackle the challenges posed by M-Commerce and that delays will significantly impact the growth resulting in loss of revenues derived from $\mathrm{M}-\mathrm{Commerce}$.

It is not only the final number of M-Commerce users that declines but a significant lag in the growth trajectory can be observed all through the simulated period from Figure 6. Over this period the average decline in M-Commerce users is $16 \%, 38 \%$ and $44.6 \%$ respectively for one, two and three years delay in policy initiatives. Thus losses in revenue for the M-Commerce eco-system stakeholders due to delay in policy measures are significant not only in the final year but throughout the simulated period. Timely Policy initiatives are, therefore, imperative as otherwise the M-Commerce industry would suffer in terms of subscriptions, adoption rates and revenues. 


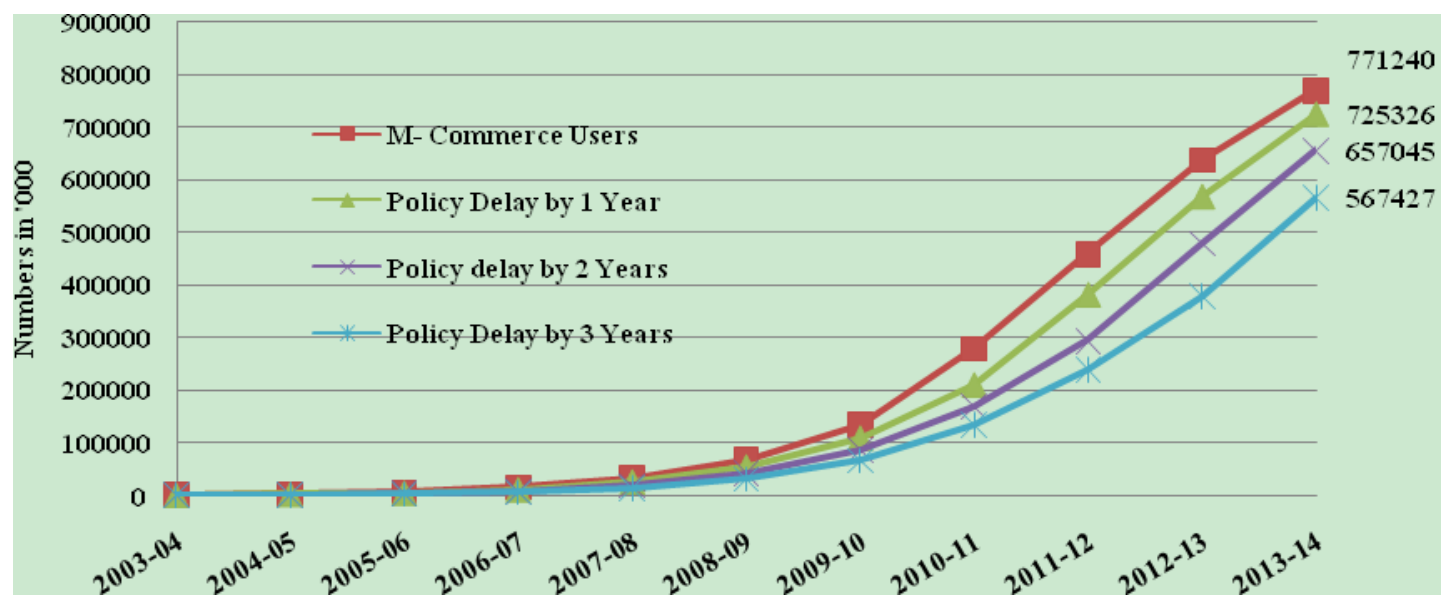

Figure 6. Effect of policies delayed in time over mobile commerce user base

\subsubsection{Scenario 2: Individual Policies Delayed in Time}

To identify policy sectors that are predominant in influencing the number of M-Commerce users, simulations are run with sector specific Policy Favourability Indicator delayed, individually, in time by one, two and three years. It is seen that the delay in individual policies by three years has the maximum retarding impact on the number of M-Commerce users compared to the delay in policies by two and one year respectively, as expected. It is further observed that the delay in Banking sector policies has the maximum retarding impact compared to the rest of the considered policy sectors. A three year delay in banking policies results in a decline by 63 million M-Commerce users in 2013-14 (8\% less compared to the base case), while the decline is 33 million (4.5\%) and 14 million (2\%) respectively for two and one year delay in Banking policies. Whereas the average impact on M-Commerce users of delays in policies in the other sectors ranges between $0.6 \%$ and $2.9 \%$ which is relatively insignificant with respect to the delays in Banking policies. The policy sectors, in order of their decreasing impact over the simulated period in M-Commerce users, are Banking (8.17\%), mobile terminal (2.87\%), Mobile policies (2.69\%), Content (1.9\%) and Retail (1.64\%) for three year delays. Thus, Banking Policies play the most critical role in M-Commerce growth and any delays in this policy sector has the largest adverse impact on the M-Commerce business eco- system.

\subsubsection{Scenario 3: Different Relative Weights for the Policy Sectors as Per Experts' Opinion}

Experts' opinion was sought through personal interviews on the relative weights that should be assigned to each policy sector. Based on their inputs, a different set of weights; Banking (15\%), Content policy (25\%), Retail Policy (15\%), Mobile Policy (25\%) and MTI Policy (20\%) were used for the policy sector factors. These differ from the earlier simulations where all the policy sectors were given equal weights of $20 \%$ each. The results indicate final M-Commerce users to be 775 million in 2013-14, which is very similar to those obtained with assignment of equal weights to all the policy sector factors. The shape of the M-Commerce adoption curve nearly overlaps in the two cases. This justifies assigning equal weights to all the policy sector factors in the base model and subsequent scenario simulations.

\subsubsection{Scenario 4: Different Individual Policy Factor Values as Per Experts' Opinion}

Experts' opinions were also elicited on the expected policy factor development over the simulated period. The suggested individual policy factor values are given in Table 2. Since only the initial and final figures are given by the experts, the growth of the individual policy factor has been assumed to be linear. The simulation results are given in Figure 7. The opinion on spectrum policy factor could not be sought as it was added later. Subsequently, the opinion on SAPF was sought from other experts and modeled. The growth based on experts input is faster than that of the base case simulation and indicates a more optimistic view of policy initiatives impacting M-Commerce users. However, the final number of M-Commerce users reaches 819 million in 2013-14 which is very similar to base case simulation results, i.e., 771 million. This indicates near stabilization of M-Commerce users by 2013-14 to $90 \%$ of mobile users and substantiates the base model simulation results. 
Table 2. Policy factor values given by experts

\begin{tabular}{cccc}
\hline Policy Factor & $\begin{array}{c}\text { Favourability } \\
\text { 2003-04/2010-11 }\end{array}$ & Policy Factor & $\begin{array}{c}\text { Favourability } \\
\mathbf{2 0 0 3 - 0 4 / 2 0 1 0 - 1 1}\end{array}$ \\
\hline RSMPF & $0.2 / 0.58$ & RePF & $0.3 / 0.81$ \\
PMPF & $0.3 / 0.68$ & TPF & $0.2 / 0.71$ \\
LEPF & $0.2 / 0.97$ & TMAPF & $0.5 / 0.88$ \\
BCPF & $0.5 / 1.0$ & ISPF & $0.3 / 0.94$ \\
MFPF & $0.2 / 0.72$ & RCPF & $0.3 / 0.94$ \\
SPPF & $0.1 / 0.87$ & FDIPF & $0.2 / 0.71$ \\
GRPF & $0.8 / 0.92$ & DSMPF & $0.2 / 0.58$ \\
CAPF & $0.3 / 0.94$ & CoPF & $0.1 / 0.74$ \\
IDPF & $0.1 / 0.87$ & LPF & $0.3 / 0.81$ \\
\hline
\end{tabular}

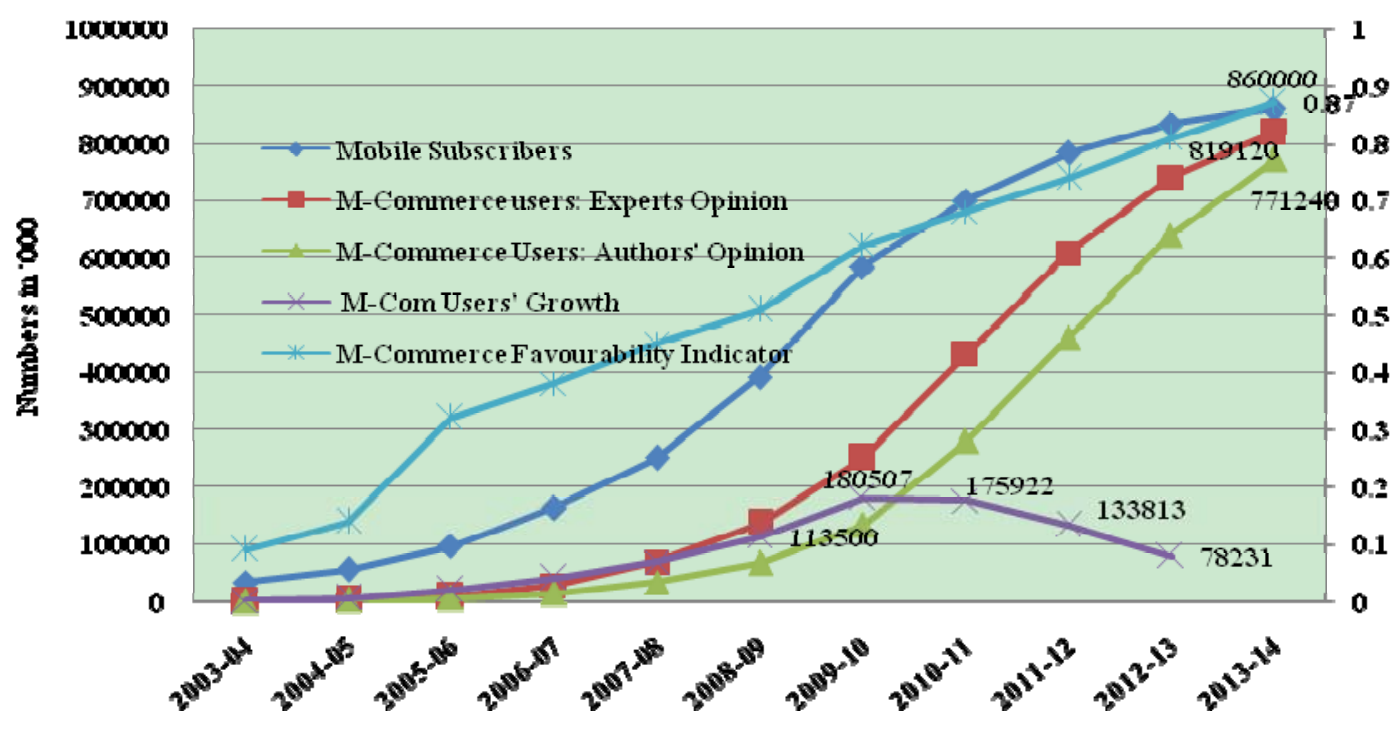

Figure 7. M-Commerce users based on policy sector factor values as suggested by experts

5.4.5 Scenario 5: Impact of Varying the Relative Weights given to Policy Favourability Indicator and User Perception

In the base case simulation the weights assumed for M-Commerce Favourability Indicator, representing favorability of total policy environment, and User Perception is 60:40. Simulations are run with different sets of weights, viz., 60:40, 80:20 and 20:80.

The results of different runs are given in Figure 8. Faster growth can be observed for the case with higher weight age to M-Commerce Favourability Indicator as compared to giving higher weight age to the User Perception. This, clearly, indicates a greater significance of policy interventions over user perception in M-Commerce growth. 


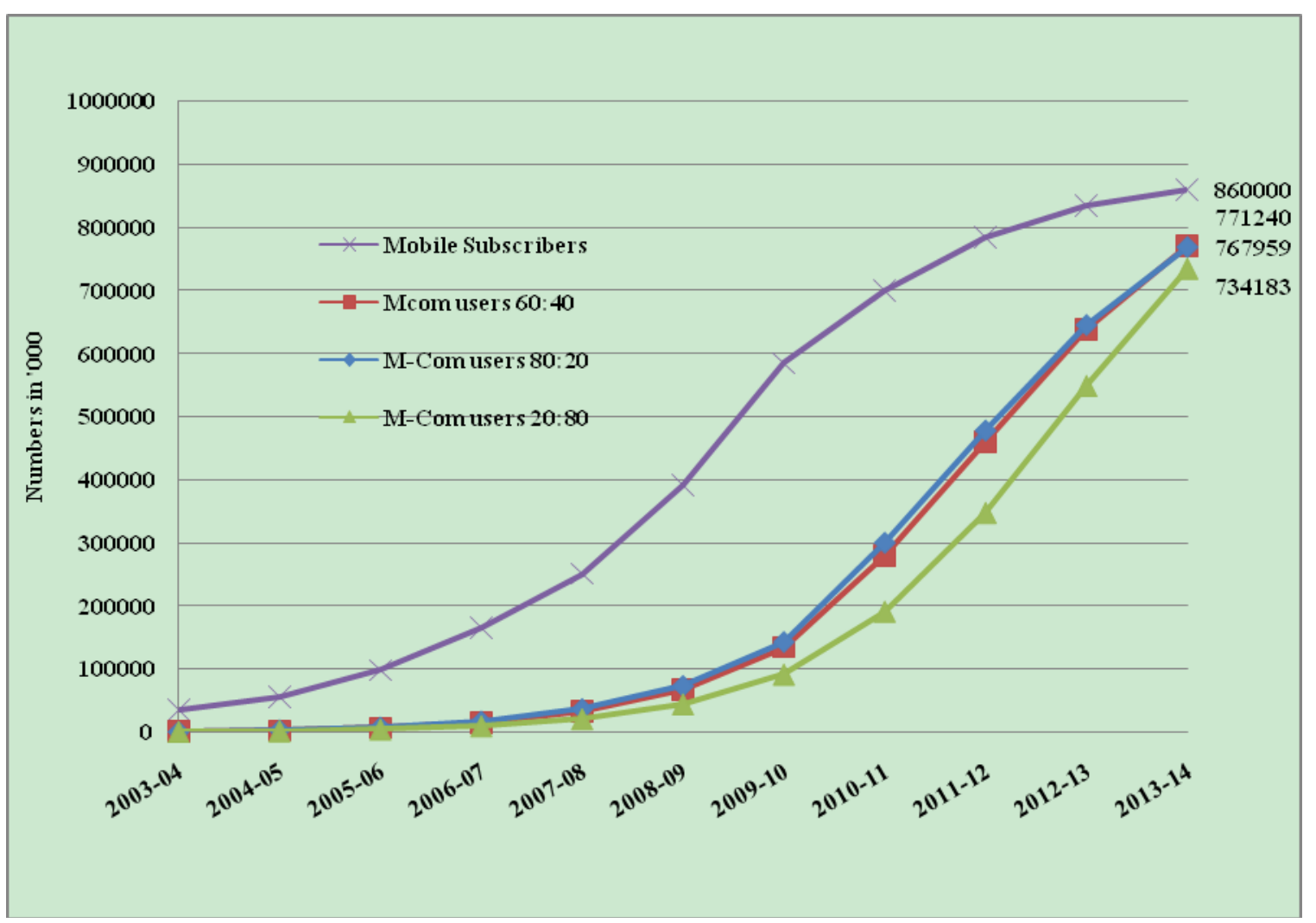

Figure 8. Impact of varying the relative weights given to M-Commerce favourability indicator and user perception

\section{Conclusions}

The regulatory paradigm of M-Commerce in India is complicated as it involves regulatory purview of more than one sectoral regulator. At present each sector has its own regulatory frameworks and agencies. The regulatory structures have to equip themselves to tackle multifaceted issues involving different independent regulators. The interrelatedness of these various subsystems is intricate. A system dynamics simulation model has been developed to understand the impact of regulations and policies in the growth of M-Commerce industry. Nineteen individual policy factors have been identified that influence the five main policy sectors, namely, banking, mobile terminal, mobile telecommunications, retail and content industries. The simulation models developed to capture the effect of policy and regulatory interventions on growth of the M-Commerce industry incorporate the intra-sector and inter-sector dependencies.

The results of the System Dynamics models indicate that M-Commerce is expected to reach substantial maturity in India by year 2013-14. The simulation results indicate that of the 860 million expected mobile subscribers in India by 2013-14, around 771 million are expected to subscribe to M-Commerce services. In the absence of a new technology paradigm, further growth in the mobile subscribers and in turn M-Commerce users would continue at a marginal level.

The growth in M-Commerce industry, at any given point of time, will come from the conversion of mobile users to mobile commerce users and existing mobile commerce users adopting higher end value added service. Once the M-Commerce industry stabilizes by 2013-14, further growth would result mainly from increased offerings in the value added services.

It is also found that time delays in policy initiatives, required for creating a favorable environment for M-Commerce applications and services, will impact the growth of the M-Commerce industry in India negatively by as much as $44 \%$ on an average over the simulated period for a delay by 3 years.

M-Commerce industry growth is a function of (i) timely policy and regulatory interventions and (ii) user perception. Of these two, it was found that policy and regulatory initiatives have a larger impact on the $\mathrm{M}$-Commerce growth than the user perception. 
Among the five policy sectors that were identified in this paper, in the Indian context, delays in banking sector policies will have higher impact on M-Commerce industry growth followed by policies pertaining to mobile terminal industry, mobile telecommunications industry, retail industry and content industry.

The System Dynamics models developed in this paper, thus, can help policy makers in understanding and analyzing the inter-dependencies among various regulatory and policy decisions and in assessing their impact on the M-Commerce business eco-system.

\section{References}

Andrew, T. N., \& Pektov, D. (2003). The need for a systems thinking approach to the planning of rural telecommunications infrastructure. Telecommunications Policy, 27, 75-93. http://dx.doi.org/10.1016/S0308-5961(02)00095-2

Baldwin, R., \& Martin, C. (1999). Understanding Regulation-Theory, Strategy and Practice. Oxford University Press: USA.

Bank of International Settlement. (2003). Payment and Settlement Systems in Selected Countries. Retrieved from http://www.bis.org/publ/cpss53.html

Barlas, Y. (1996). Formal aspects of model validity and validation in system dynamics. System Dynamics Review, $12(3)$,

183-210. http://dx.doi.org/10.1002/(SICI)1099-1727(199623)12:3<183::AID-SDR103>3.0.CO;2-4

Bianchi, C., \& Bivona, E. (2002). Opportunities and pitfalls related to E-Commerce strategies in small-medium firms: a system dynamics approach. System Dynamics Review, 18(3), 403-429. http://dx.doi.org/10.1002/sdr.256

Business Monitor International. (2006). The India Business Forecast Report Q3 2006.

Clarke, III. I. (2001). Emerging value propositions for M-commerce. Journal of Business Strategies, 18(2), $133-$ 148.

Coai. (2007). Annual Report 2006-07. Retrieved http://www.coai.com/docs/COAI\%20Annual\%20Report\%20Final\%20Annexure-3.pdf
Coai.
(2010).
Annual
Report
2009-10.
Retrieve
from http://www.coai.com/docs/COAI\%20Annual\%20Report\%202009-10.pdf

Crisinfac. (2006). Telecom Services Annual Review, August 2006.

Crisinfac. (2007c). Industry Statistics.Crisil Research Telecom Services Update, January 2007.

Crisinfac. (2008). Telecom Services. Crisil Research Telecom Services Monthly Report, October 2008.

Crisinfac. (2010a). Annual report on Telecom Services. Crisil Research Telecom Services Annual Review, May 2010.

Crisinfac. (2010b). Annual report on Telecom Data Services. Crisil Research Telecom Services Annual Review, January 2010.

Crisinfac.(2007a). Opinion. Crisil Research Telecom Services Annual Review, November 2007.

Crisinfac.(2007b). State of the Industry. Crisil Research Telecom Services Annual Review, October 2007.

Department of Industrial Policy and Promotion. (2010). FDI statistics for June 2010. Retrieved from http://www.dipp.nic.in/English/Publications/FDI_Statistics/2010/india_FDI_November2010.pdf

Dyer, J. H., \& Singh, H. (1998). The Relational View: Cooperative Strategy and Sources of Interorganizational competitive advantage. Academy of Management Review, 23(4), 660-79.

Euromonitor International. (2010). E-Payment on the rise.

Forrester, J. W. (1996). Obvious Truths. System Dynamics Review, 3(2), 156-159. http://dx.doi.org/10.1002/sdr.4260030207

Gary, M., Grant, C. N., \& Dalzell, B. (2004). A dynamic model of mobile telephony subscription incorporating a network effect. Telecommunications Policy, 28, 133-144. http://dx.doi.org/10.1016/j.telpol.2003.12.002

GSM Association Report. (2006). Tax and the Digital Divide.

Heijden, H. (2002). Factors Affecting the Successful Introduction of Mobile Payment Systems. In 15th Bled Electronic Commerce Conference, Slovenia. Retrieved from 
http://www.bledconference.org/proceedings.nsf/Proceedings/F307589C02242840C1256E9F003528BD/\$Fi le/heijden.pdf

Henten, A., Samarajiva, R., \& William, M. (2003). Designing Next Generation Telecom Regulation: ICT Convergence or Multi-sector Utility Regulation. Info, 5(1), 26-31. http://dx.doi.org/10.1108/14636690310473863

IAMAI Report. (2008). Mobile Value Added Services in India.

IDC Report. (2010). Retrieved form http://www.idcindia.com/analyst_viewpoint/index.asp

India Reports. (2009). E-Commerce in India a Review. Chillibreeze Publishing.

Karjaluoto, H. (2006). An Investigation of Third Generation (3G) Mobile Technologies and Services. Contemporary Management Research, 2(2), 91-104.

Krishnamurthy, S. (2001). NTT DoCoMo's i-Mode Phone: A Case Study. Retrieved from http://www.swlearning.com/marketing/krishnamurthy/first_edition/case_updates/docomo_final.pdf

Krueger, M. (2001). The future of M-payments: business options and policy issues. Background Paper, 2. Retrieved from http://epso.intrasoft.lu/papers/Backgrnd-2.pdf

Lee, C., Hu, W. C., \& Yen, J. (2003). A System Model for Mobile Commerce. In IEEE, 23rd International Conference on Distributed Computing Systems Workshop.

Lehner, F., \& Watson, R. (2001). From E Commerce to M Commerce-Research Directions. Retrieved from http://www.ebusinessforum.gr/engine/index.phpop=modload\&modname=Downloads\&action=downloadsvi ewfile\&ctn $=927 \&$ language $=\mathrm{el}$

Lin, H., \& Wang, Y. (2005). Predicting Consumer Intention to use Mobile Commerce in Taiwan. In International Conference on Mobile Business, IEEE.

Mass, N. J. (1991). Diagnosing surprise model behavior: a tool for evolving behavioural and policy insights. System Dynamics Review, 7(1), 68-86. http://dx.doi.org/10.1002/sdr.4260070106

McKinsey Company. (2006). Wireless Unbound-The surprising economic value and untapped potential of Mobile Phone.

Mohapatra, P. K. J., Mandal, S., \& Bora, M. C. (1994). Introduction to System Dynamics Modeling. University Press (India) Ltd.

Mylonopoulos, N., \& Doukidis, G. I. (2003). Mobile business: Technological pluralism, social assimilation, and growth. International Journal of Electronic Commerce, 8(1), 5-22.

Ngai, E. W. T., \& Gunasekaran, A. (2007). A Review for Mobile Commerce Research and Applications. Decision Support Systems, 43, 3-15. http://dx.doi.org/10.1016/j.dss.2005.05.003

OECD Report. (2000). Reducing the Risk of Policy Failure: Challenges for Regulatory Compliance. Retrieved from http://cccp.anu.edu.au/Published_OECD_Report2.pdf

Okazaki, S. (2005). New Perspectives on Mobile Commerce Research. Journal of Electronic Commerce Research, 6(3), 160-164.

Oliva, R., Sterman, J. D., \& Martin, G. (2003). Limits to Growth in the new economy: exploring the 'get big fast' strategy in E-Commerce. System Dynamics Review, 19(2), 83-117. http://dx.doi.org/10.1002/sdr.271

Park, B. W., \& Ahn, J. H. (2010). Policy Analysis for Online game addiction problems. System Dynamics Review, 26(2), 117-138. http://dx.doi.org/10.1002/sdr.436

Pedersen, A. F., Jelbo, C., \& Andersen, K. V. (2003). The paradox of the mobile internet: Acceptance of gadgets and Rejection of innovations. In 16th Bled e-Commerce Conference. Slovenia.

Petri, R. (2006). Diffusion of digital mobile telephony: Are developing countries different? Telecommunications Policy, 30, 46-63. http://dx.doi.org/10.1016/j.telpol.2005.06.014

Post, J. E., Lee, E. P., \& Sybille, S. (2002). Redefining the Corporation: Stakeholder Management and Organizational Wealth. Stanford University Press.

Purohit, M. C., \& Purohit, V. K. (2005). E-Commerce and Economic Development. Retrieved from http://www.saneinetwork.net/research/sanei_VI/abstract8.asp

Rogers, E. M. (1983). The Diffusion of Innovations (3rd Edition). Free Press: New York. 
Salvi, A. B., \& Sahai, S. (2002). Dial M for Money. In 2nd International Workshop on Mobile Commerce. Atlanta, Georgia, USA. http://dx.doi.org/10.1145/570705.570723

Samarajiva, R., Mahan, A., \& Brendse, A. (2002). The Multi sector Utility Regulation. World Dialogue on Regulation in Network Economies. Discussion Paper No. 203.

Sara, B. (2011). Behind the scenes of the telecommunications miracle: An empirical analysis of the Indian market. Telecommunications Policy, 35, 238-249. http://dx.doi.org/10.1016/j.telpol.2010.12.011

Sharma, D. (2007). Evaluating the Impact of Government Policies and Regulation: A System Dynamics Modeling Approach. Unpublished Dissertation: Post Graduate Program in Public Policy and Management, Indian Institute of Management, Bangalore, India.

Spyrelli, C. (2004). Regulating the Regulators? An assessment of institutional structures and procedural rules of national regulatory authorities. International Journal of Communications Law and Policy, 8, 1-65.

Stanford-BDA Analysis Report. (2007). Future of Mobile VAS in India. Retrieved from www.bdaconnect.com

Sterman, J. D. (2000). Business Dynamics: Systems Thinking and Modeling for a Complex World. Irwin McGraw-Hill: Boston. MA.

Sundar, D. K., \& Garg, S. (2005a). M-Governance: A framework for Indian Urban Local. In Euro mGov 2005, University of Sussex, UK.

Sundar, D. K., Garg, S., \& Garg, I. (2005b). M-Governance: A mobile computing framework for integrated disease surveillance in India. In Euro M-Gov 2005. University of Sussex, UK.

Sundar, D. K., Garg, S., \& Ramanayya, T. V. (2002). Integrated virtual logistics network for quick responses. In ICTTS: $1224-1231$.

Sundar, D. K., Murthy, R. V., \& Sharma, D. (2006). Government Policies and Regulations: Impact on Mobile Commerce in Indian Context. In Second International Conference on Mobile Governance, Sussex University, U.K.

Thomas, R. C., \& Juuso, T. (2012). Mobile voice diffusion and service competition: A system dynamic analysis of regulatory policy. Telecommunications Policy, 36, 162-174. http://dx.doi.org/10.1016/j.telpol.2011.07.002

TRAI Report (2004). The Indian Telecom Services Performance Indicator Report, Jan 04-Mar 04. Retrieved from http://www.trai.gov.in/WriteReadData/PIRReport/Documents/indireport230604.pdf

TRAI Report. (2005a). Indicators for Telecom Growth. Retrieved from http://www.trai.gov.in/Content/StudyPaperDescription.aspx?STUDYPAPER_ID=63\&qid=1

TRAI Report. (2006). Annual Report, 2005-06. Retrieved from http://www.trai.gov.in/Content/PerformanceIndicatorsReports.aspx?ID=1\&qid=1

TRAI Report. (2007). Annual Report, 2006-07. Retrieved from http://www.trai.gov.in/Content/PerformanceIndicatorsReports.aspx?ID=1\&qid=1

TRAI Report. (2008). The Indian Telecom Services Performance Indicator Report. Retrieved April 08-Jun 08 from http://www.trai.gov.in/WriteReadData/PIRReport/Documents/report7oct08.pdf

TRAI Report. (2009). The Indian Telecom Services Performance Indicator Report. Retrieved July 08-Sept, 08 from http://www.trai.gov.in/WriteReadData/PIRReport/Documents/Report13jan09.pdf

TRAI Report. (2010). The Indian Telecom Services Performance Indicators. Retrieved Jan 10-Mar 10 from http://www.trai.gov.in/WriteReadData/PIRReport/Documents/finalperformanceindicatorReport9agust.pdf

TRAI Report.(2005b). The Indian Telecom Services Performance Indicator Report. Retrieved Jan 05-Mar 05 from http://www.trai.gov.in/WriteReadData/PIRReport/Documents/reports17jun05.pdf

Udo, G. J. (2001). Privacy and security concerns as major barriers for E-Commerce: a survey study. Information Management and Computer security, 9(4), 165-174. http://dx.doi.org/10.1108/EUM0000000005808

Vaithianathan, S. (2010). A review of e-commerce literature on India and research agenda for future. Electronic Commerce Research, 10, 83-97. http://dx.doi.org/10.1007/s10660-010-9046-0

Varshney, U., \& Vetter, R. J. (2002). Mobile Commerce: Framework, Applications and Networking Support. Mobile Networks and Applications, 7(3), 185-198. http://dx.doi.org/10.1023/A:1014570512129

Varshney, U., Vetter, R. J., \& Kalakota, R. (2000). Mobile Commerce: A New Frontier. Computer, 33(10), 32-38. 
http://dx.doi.org/10.1109/2.876290

Venkatesh, V., Morris, G., Davis, G. B., \& Davis, F. D. (2003). User Acceptance of Information Technology: Toward a Unified View. MIS Quarterly, 27(3), 115-139.

Walshe, K. (2002). The rise of Regulation in the NHS. BMJ, 324, 967-970. http://dx.doi.org/10.1136/bmj.324.7343.967s

Wang, J. J., Song, Z., Lei, P., \& Sheriff, R. E. (2005). Design and Evaluation of M-Commerce Application. In Asia-Pacific Conference on Communications IEEE, Perth, Western Australia: 745-749.

Wang, W., \& Cheong, F. (2005a). Using System Dynamics to simulate the Strategic Planning of Mobile Commerce Terminal Industry and Mobile Commerce Diffusion. The International Conference on Mobile Business, 420-426.

Wang, W., \& Cheong, F. (2005b). A framework for system dynamic modeling of the mobile commerce market. International Congress on Modeling and Simulation Modsim, 5, 1787-1793.

Wong, C. C., \& Hiew, P. L. (2005). Factors Influencing the Adoption of Mobile Entertainment: Empirical Evidence from a Malaysian Survey. International Conference on Mobile Business, 682-685.

Yan, C., \& Li, H. H. (2005). Mobile business applications adoption based on the concepts of task/ technology Fit. IEEE: $1346-1350$.

Notes

Note 1. TRAI Chairman, Telecom Regulatory Authority of India

Note 2. BSNL Board Member, New Services, Bharat Sanchar Nigam Limited, the public mobile operator in India

Note 3. NEGP Advisor, National E-Governance Program 
Appendix 1. Impact of Policy and Regulatory changes on mobile industry in India

Figure 9 illustrates the impact of regulatory interventions on the subscription prices and number of mobile subscribers.

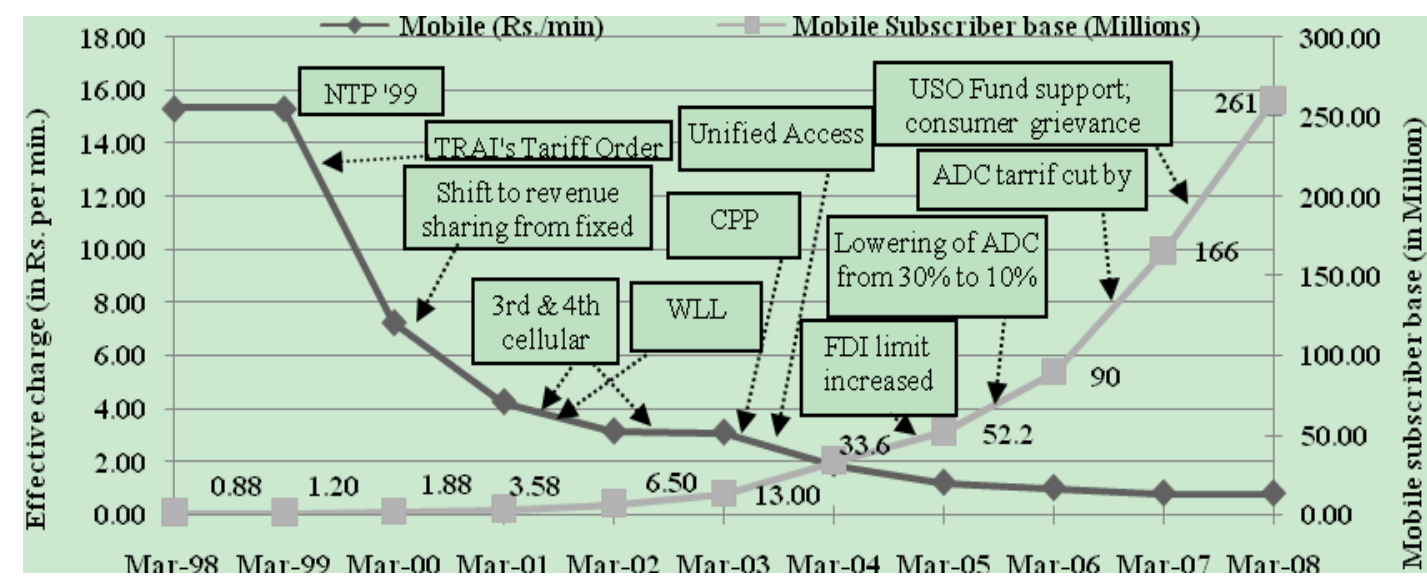

Figure 9. Mobile growth and effective charge per minute important regulatory and policy initiatives that led to growth

Appendix 2. Policy Factors and Equations for the Simulation Models

SAPF: Spectrum Allocation Policy factor

Availability and pricing of spectrum is a major cost component of wireless services. $2 \mathrm{G}$ operators faced spectrum shortage by 2007 and new $2 \mathrm{G}$ licenses and spectrum were given in $2008.3 \mathrm{G}$ spectrum in India was auctioned in mid-2010 at high prices but will allow operators to provide differentiated services and increase average revenue per user (ARPU), particularly to high end users, due to enhanced service portfolio.

Equation: The value of SAPF is taken as 0.1 up to 2007 indicating spectrum crunch being faced by the industry and increased with a slope of 0.1 till 2009reflecting additional licenses. The slope is increased to 0.15 after 2010 when 3G services were rolled out to make the SAPF value 1 by 2014.

BCPF: Banking Code Policy Factor

Banking Code and Standards Board of India (BCSBI) and RBI implemented the Banking Code for Indian banks and financial institutions in 2006. BCBSI also acts as a watchdog to monitor and ensure compliance of accepted codes. 102 banks of all genres are registered with BCBSI and have agreed to abide by the code by 2010 .

Equation: The values for BCPF, is taken as 0.1 initially indicating self-compliance till 2006, 0.35 in 2006-07 to indicate declaration of Banking Code and an increase by 0.05 annually till 2011 assuming wider adoption of Banking Code. BCPF value increases at 0.15 post 2011 indicating rigorous compliance efforts required by $\mathrm{BSBCI}$ in $3 \mathrm{G}$ era.

\section{MFPF: Microfinance Policy Factor}

Micro finance demand estimations for India stand at INR 1,500,000 million and only INR 220,000 million was disbursed till 2008. Variants for micro finance disbursement through mobile technology are being experimented with since 2006 and can play an important role in filing the gap at lower costs. Policy space for innovation that can bring confidence amongst the masses in transactions carried through mobile technology is required.

Equation: As the policy for micro finance is still evolving the MFPF is initially taken to be 0.1 till 2006 . Thereafter, reflecting an expected slow improvement in the policy environment the value is 0.4 till 2012 after which it increases rapidly to 0.7 by $2013-14$ considering the confidence in $3 \mathrm{G}$ era. 


\section{SPPF: Security and Privacy Policy Factor}

Data security and privacy are major concerns for individuals using E-Commerce transactions. Internet banking and transactions have been made very secure in India by Reserve bank of India (RBI) rules and guidelines which has resulted in a burgeoning E-Commerce industry. However, the same is not the case with mobile commerce.

Equation: The factor value is taken to be 0.1 initially till 2007 signaling no policy guidelines for mobile payments and the security resting with mobile operators. The factor value is made 0.3 to reflect RBI guidelines on mobile payments in 2008-09, subsequent increase at rate of 0.05 till 2012. The value rises at a rate of 0.2 after 2012reflecting wider adoption of $3 \mathrm{G}$ that would demand further policy formulations.

RSMPF: Revenue Sharing Mechanism Policy Factor

In India revenue sharing between mobile operator, content provider and content aggregator is skewed in the ratio of 60:30:10 with mobile operators charging a premium on account of their direct consumer interaction. In matured markets operator share is much lower, $9 \%$ for Japan and 16\% for China. Given the unequal bargaining power there is a need for regulatory intervention which can be limited to the time of market maturity.

Equation: There were no policy corrections till 2008(IAMAI, 2008) reflected by RSMPF value as 0.1 . The power balance improves as more complex services based on mobile games, social networking etc., are offered. This is reflected by an increased rate of 0.1 till 2011 and 0.15 later in $3 \mathrm{G}$ era.

\section{LEPF: Legal Environment Policy Factor}

Red ressal mechanisms for consumer complaints and other intermediaries in M-Commerce value chain are required at low costs. With increasing complexity of applications and services newer issues will emerge. These will necessitate adaptations in legal system over time.

Equation: The LEPF factor value has been taken to be 0.05 initially \& improves at a rate of 0.05 till 2010. The rise is faster after 2010 at a rate of 0.1 as better governance mechanisms are needed post $2010 \mathrm{in} 3 \mathrm{G}$ era to make it 0.75 by $2013-14$.

\section{PMPF: Payment Mechanism Policy Factor}

There are many challenges for banks, telecom companies, retailers and regulators in facilitating and standardizing mobile payments. The first three have to be well integrated in order to provide network independent ubiquitous services and the latter has to protect consumer interests. Suitable payment mechanisms are expected to be in place in the next five years driven by market requirements and user convenience.

Equation: The PMPF is 0.1 initially till 2008 reflecting payment facilitations through mobile operator after which it improves with slope of 0.05 till 2011 to reflect simple payment mechanisms facilitating mobile ticketing and mobile recharge. The slope is subsequently increased to 0.2 to reflect POS and mobile wallet facilitations.

\section{CAPF: Content Availability Policy Factor}

The Indian VAS industry draws major revenues from film music industry (CRISINFAC, 2010b) in form of music, wall papers, film based games and advertisements.TV on mobile networks is another possibility in $3 \mathrm{G}$ services. The challenge lies in translating the content to mobile compatible form. With a mature software industry, numerous content aggregators \&low entry barriers, the industry has a lot to gain from MVAS.

Equation: The value for CAPF is taken as 0.1 initially and rises steadily at a slope of 0.05 till $2009,0.1$ further till 2012 and 0.2 later to reflect complexity of available content.

\section{GRPF: Gaming Regulations Policy Factor}

Technology for Digital Rights Management for mobile games and IPR protection for game developers exists in handsets. India does not have internet specific gaming laws for protection of minors from vulnerability of online gambling though gambling in general is prohibited. Steps towards regulating internet and mobile gaming need to be initiated.

Equation: The factor has been taken as zero until 2007 indicating no online gaming activities on mobile. Thereafter it is increased with a slope of 0.05 till 2012 expecting some gaming regulations in place. The slope is increased to 0.2 from 2012onwards to indicate increased mobile gaming in $3 \mathrm{G}$ era will induce regulatory actions.

\section{IDPF: Import Duty Policy Factor}

New Telecom Policy 1994 (NTP-94) had provisions to encourage local telecom equipment manufacturing 
industry and NTP-99 reiterated this provision.This along with SEZ benefits, tax holidays and availability of skilled and cheap work force boosted telecom manufacturing in India. The telecom-manufacturing share in overall electronics production in India grew from $21 \%$ in 2006 to $41 \%$ by 2009 . Manufacturers demand further policy efforts to bring down excise duties from $14 \%$ to $4 \%$.

Equation: The value of IDPF is taken as 0.1 till 2005 indicating high duties. ITA implementation is reflected by a slope of 0.2 till 2007-09. Subsequently, the factor improves at reduced rate of 0.1 per year reflecting continued benefits of earlier efforts.

\section{REPF: Retail Policy Factor}

Retailers are major players in the mobile commerce value chain and policies pertaining to retail sector would decide the mobile business figures. Indian retail market is fifth largest in world with revenues worth INR 21,350 billion in 2010 and expected to rise to INR 31850 billion by 2015 . The market is mainly operated by small scale businessmen who would be reluctant to bear the transaction costs in mobile domain. However, the e-tail is doing well and was estimated at INR 11 billion in 2008. The industry has presence of big groups who are expected to enter the mobile domain also.

Equation: Given the nascence of retail markets the value for RePF is taken as 0.05 initially till 2008 , rises with a slope of 0.05 till 2012 reflecting service/ticket sales on mobile and increases fast at the rate of 0.2 , reflecting increased sales in $3 \mathrm{G}$ era and hence policy demands.

\section{ISPF: Infrastructure Support Policy Factor}

Infrastructure for telecom services created by service providers extends coverage to most cities but rural areas lag behind. Universal Access policy of the government is fostering roll out in rural areas by allowing infrastructure sharing and subsidizing costs of infrastructure. Infrastructure support from USO funds was provided by the government in 2007to construct more than 7000 towers that extended coverage in more than 200,000 villages. The next phase in 2010 was to support more than 11000 towers.

Equation: ISPF is taken as 0.1 till 2006 reflecting no policy support. Phase I of infrastructure support from 2007 onwards is reflected by a slope of 0.1 and ISPF reaches 0.4 in 2010. Phase II support is indicated by a slope of 0.15 to make ISPF 1 by2013-14.

\section{TPF: Taxation Policy Factor}

Taxation can lead to high costs of handsets and services, be a barrier for use and also lead to development of gray markets as per a study conducted in 50 countries by the GSM Association in 2006. Removal of all sales and customs taxes on handsets and taxes on services could prompt an increase in mobile penetration of up to 20 percentage points. The study cited example of Indian industry which has boosted mobile penetration from $1 \%$ to $5 \%$ in three years by reducing duties.

Equation: The policy factor has been taken as 0.07 in 2003-04 and it is given a final value of 0.77 in 2014increasing linearly throughout.

\section{RCPF: Regulatory Charges Policy Factor}

Presently charges payable by mobile operators in India are higher than those applicable in neighboring countries (CRISINFAC, 2006). The license fees were reduced from $15 \%$ of AGR for all operators in $1999-2000$ to $12 \%$, $10 \% \& 8 \%$ of AGR for Metro/Category A circle, Category B\& C circles respectively in 2001. It was further reduced by $2 \%$ in 2004. In October 2008 DOT announced roll out coverage incentives by reducing the annual revenue share license fee for operators achieving over 95\% coverage in their service areas (except metros) by $2 \%$ points. The license fees are expected to be reduced further to $4 \%$ of AGR by 2013 . These measures would reduce the license cost of the operators and the benefits are likely to be transferred to subscribers.

Equation: The value for RCPF is taken to be 0.3 in 2003-04 and steadily increases to 0.6 by 2009. Thereafter, it improves faster to be 1 by 2013-14 by when it is expected that the regulatory charges for mobile services will be at par with rates in other countries.

\section{DSMPF: Dispute Settlement Mechanism Policy Factor}

For overall growth of the industry, the state has to ensure consumer protection. The functioning of Consumer courts for same is not very efficient.

In the telecommunication sector the Telecom Dispute Settlement Authority (TDSAT) and in banking the Central Bank acts as the regulator. TDSAT has been fairly successful in resolving inter-player disputes. However, the dispute settlement mechanisms in place are inadequate to deal with the new issues arising out of transactions in 
M-commerce. We expect that there would be sufficient provisions to deal with the problems by 2014 .

Equations: The DSMPF value has been taken initially as 0.2 in 2003-04. No specific regulatory initiative to address complex issues exist and the improvement is expected to happen mainly through experience, indicated by a slope of 0.05 to make it 0.7 by 2014 .

\section{COPF: Competition Policy Factor}

India shifted from monopoly restriction regulation to competition regulation with establishment of Competition Commission of India (CCI) in 2002. CCI took more than five years to become fully functional due to institutional conflicts and the system is expected to take time to sort out regulatory purview issues among CCI and other sectoral regulatory authorities and effectively regulate competition.

Telecom regulator has stated guidelines for considering significant market power, monopoly power, and intra-circle mergers and acquisitions.

Equation: This policy factor has been given a value of 0.2 initially in 2003-04 and a ramp function with a slope of 0.06 till 2012 indicating no major development but a constant evolution of policies and system with experience over time. Later in $3 \mathrm{G}$ environment things are expected to move faster as indicated by a slope of 0.1 .

\section{FDIPF: Foreign Direct Investment Policy Factor}

The FDI policy which earlier allowed 49\% FDI in telecom was relaxed in October 2005 to allow $74 \%$ in telecom services such as basic, cellular mobile and internet service provision. The limit is $100 \%$ in telecom manufacturing sector and infrastructure provision. Policy relaxations and sector growth have seen telecom sector FDI, as a percentage of total FDI, increase from $9.7 \%$ in 2004-05 to $33 \%$ in 2009-10.

Equation: The factor value is taken to be 0.2 in $2003-04$ since $49 \%$ FDI was permitted and 0.4 in 2005 to indicate increased FDI. It reaches a value of 0.9 in 2014 reflecting that FDI policies and FDI inflows are expected to continue to be favorable.

TMAPF: Technical Manpower Availability Policy Factor

The availability of technical manpower for the telecom manufacturing, telecom operations, content development and content aggregation etc. is a prerequisite for development of the industry. India has a strong foothold in technical expertise and software development.

Equation: TMPAF is taken to be 0.5 initially reflecting availability of technically skilled manpower for establishing networks and manufacturing sector. The factor value increases continuously to make it 1 in 2014 reflecting human capital development in developing applications and services for M-Commerce.

\section{LPF: Labour Policy Factor}

Strict labour laws existing in India govern the hiring and firing of employees and are tighter than most South Asian states and substantially tighter than the high income OECD countries. According to the World Bank's employment laws index, score of India is 51 which indicate a heavily regulated labour force.

Equation: The initial value for this factor has been taken at 0.3 . Since no radical policy initiatives are there or expected in future due to the coalition forms of governments (Business Monitor International, 2006), a time gap is expected in policies becoming completely favorable. The value is assumed to grow linearly to reach 0.8 by 2014. 